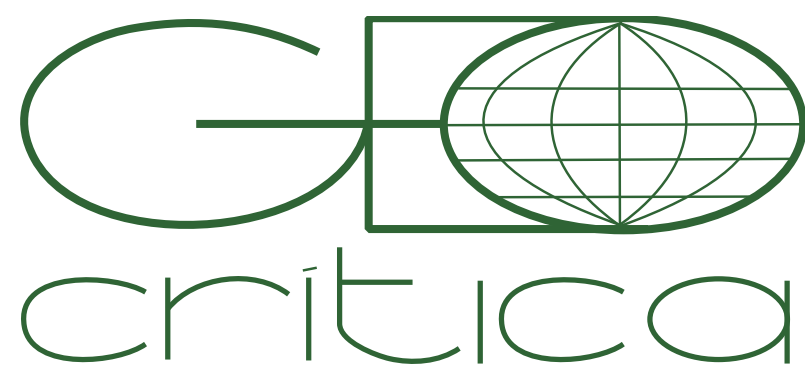

Revista Electrónica de Geografía y Ciencias Sociales Universitat de Barcelona

ISSN: $1138-9788$

Vol. 25, Núm. 2 (2021), p. 271-306

\title{
LA REVOLUCIÓN RESIDENCIAL DE LA PERIFERIA OBRERA EN BARCELONA, 1939-1980: NOU BARRIS COMO ESTUDIO DE CASO
}

\author{
José Luis Oyón \\ Manel Guàrdia \\ Universitat Politècnica de Catalunya (UPC), Escuela de Arquitectura del Vallés (ETSAV) \\ jose.luis.oyon@upc.edu \\ manel.guardia@upc.edu \\ Maribel Rosselló \\ David H. Falagán \\ Universitat Politècnica de Catalunya (UPC), Escuela Politécnica Superior de Barcelona (EPSEB) \\ maribel.rosselló@upc.edu \\ david.hernandez.falagan@upc.edu \\ Joan Roger Goncé \\ Universitat Politècnica de Catalunya (UPC) \\ joan.roger@upc.edu
}

Este artículo es resultado del proyecto de investigación ‘La revolución del entorno cotidiano obrero y popular. Vivienda y espacio urbano en el distrito de Nou Barris de Barcelona, 1950-1975' (Plan Nacional, HAR2017-82965-R)
Recibido: 26 septiembre 2020; Devuelto para correcciones: 9 febrero 2021; Aceptado: 1 marzo 2021

\section{La revolución residencial de la periferia obrera en Barcelona, 1939-1980: Nou Barris como estudio de caso (Resumen)}

El artículo forma parte de un proyecto más amplio que pretende resaltar que la revolución de la vivienda del segundo franquismo no fue solo una revolución de las formas urbanas, de brusco cambio en las formas de ocupación de la vivienda y en el tipo de familia, de radical renovación del equipamiento doméstico, sino también una revolución de la propiedad de la casa. Esta última revolución tuvo en los barrios obreros de la periferia barcelonesa y de las grandes ciudades españolas su auténtico caballo de Troya y constituyó una auténtica excepcionalidad a nivel europeo.

Palabras clave: Nou Barris, periferias obreras, polígonos, densificación, vivienda en el franquismo.

The residential revolution of Barcelona working-class suburbs, 1939-1980: Nou Barris as case study (Abstract)

This article is part of a broader research project that aims to highlight how the housing revolution during the second part of Franco regime was not only a revolution of urban forms, of abrupt change in the forms of housing occupation and in the type of family, of radical renovation of domestic equipment, but also a revolution of home ownership. This last revolution had its true Trojan horse in the working-class neighborhoods of Barcelona and other large Spanish cities periphery, and constituted an actual exception at an European level.

Keywords: Nou Barris, working-class suburbs, housing estates, densification, housing under the Franco regime. 
En la generalizada transformación residencial de las periferias obreras durante las décadas de la segunda postguerra mundial, la diversidad de contextos y la extrema complejidad de los procesos no permiten establecer pautas y reglas de orden general. Es aconsejable empezar por la exploración sistemática de estudios de caso, mediante el uso exhaustivo de todas las fuentes disponibles, para hacer aportaciones útiles y significativas; tanto para las aproximaciones comparadas, como para la comprensión del contexto histórico y de los procesos de orden más local.

En el caso de las grandes ciudades españolas, la formidable transformación residencial de sus periferias obreras durante el franquismo (Brandis 1983) ha sido generalmente abordada en los estudios de historia económica del sector de la construcción (Tafunell 1989; Sorribes 2015) o en los de geografía urbana (Llordén 1978; Vilagrasa 1990, 1997; Canosa 1995; Rodríguez 2001; Medina Saiz 2004) desde la perspectiva de la producción inmobiliaria y no tanto desde el consumo. Desde la "oferta" y no desde la "demanda". En el caso de la historia de la arquitectura y del urbanismo se ha privilegiado en particular la dimensión morfológica (Solà-Morales 1997; Busquets 1999) y de gestión urbanística de las grandes operaciones de vivienda masiva (Ferrer 1996; Gigosos y Sarabia 1997; Monclús y Díez 2016; Díez Medina y Monclús 2020).

Pero como señala Amador Ferrer para el área metropolitana de Barcelona, el enorme impacto de los polígonos de viviendas de estos años puede confundir. Porque, mientras la mitad del nuevo suelo urbanizado en la comarca entre 1960 y 1970 se dedicó a los polígonos, éstos apenas aportaron un tercio del total de viviendas construidas durante el período. Se dio en paralelo un intenso proceso de densificación de los tejidos existentes (Ferrer 1996, 42). Las periferias obreras no se formaron sobre una tabula rasa. Hay que considerar las herencias, las diferencias y los procesos. Como el aumento de la dimensión conlleva un aumento de la complejidad (Sennett 2019, 132-134), la aproximación empírica a un caso de estudio adecuado bien documentado permite una exploración integrada y más relacional de la gran transformación de las periferias residenciales obreras durante el franquismo.

Nou Barris, un distrito barcelonés creado por la división administrativa de 1983 y dividido en trece barrios, resulta sin duda un buen caso de estudio. Entre 1949 y 1983 formaba parte del distrito 9 (figura 1a), centrado en el antiguo municipio de Sant Andreu. De carácter marcadamente obrero y popular, fue con diferencia el distrito de mayor crecimiento entre 1950 y 1975, como puede observarse en la figura 1b basada en datos estadísticos municipales. Dentro del distrito 9 y dentro del municipio, el crecimiento de Nou Barris fue el más explosivo: cuando la población de Barcelona solo se multiplicó por 1,5 entre esos años la de Nou Barris se multiplicó por 11,5. Dentro del no muy extenso municipio de Barcelona, es indudablemente el sector más representativo de la periferia residencial obrera y popular de la aglomeración metropolitana, y un buen exponente de la gran transformación de las periferias obreras de las grandes ciudades españolas entre los inicios de la década de los años 50 y el final de la década de los 70. No hay dentro del municipio barcelonés una zona de signo más claramente obrero e inmigrante. En 1970 dos terceras partes de sus habitantes eran trabajadores/as, cuando el porcentaje para el conjunto de Barcelona era del $48,4 \%$, muy por 
encima pues de cualquier otro distrito (figura 1c). Finalmente, es el área en la que inciden una mayor cantidad y variedad de polígonos de vivienda en un contexto también muy diverso de tejidos residenciales, no sólo de autoconstrucción sino muy especialmente de densificación de barrios ya existentes. Esta confluencia de factores convierte a Nou Barris en una buena piedra de toque para una primera aproximación integrada y relacional.
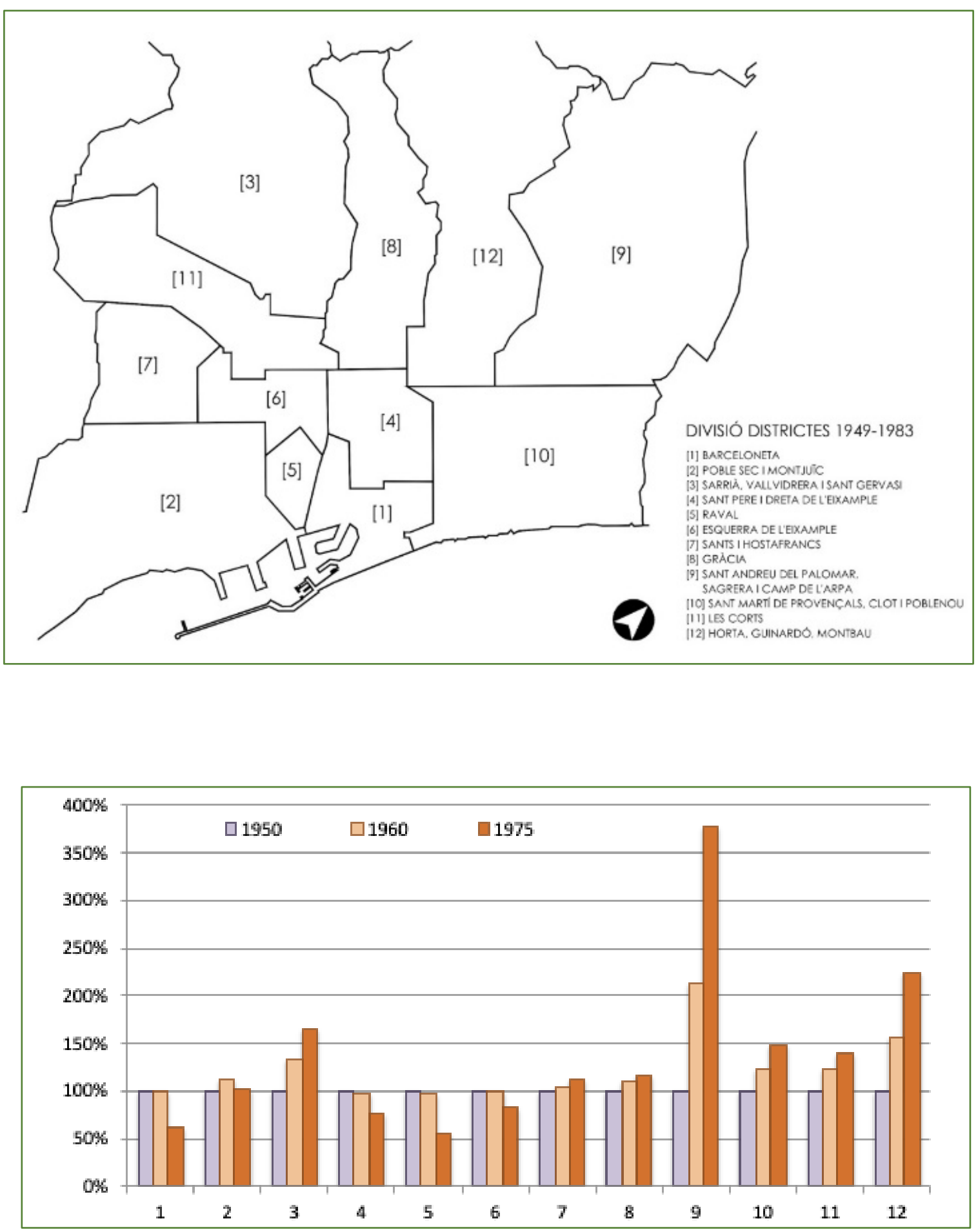
Desde su eclosión durante el franquismo, Nou Barris ha sido objeto de aproximaciones muy diversas. Desde el informe de los párrocos de Santa Engracia y de San Sebastián (Juncà y Puga 1958), los artículos sobre el estudio de Roquetes (CEDEC 1963; Donato 1965), sobre Trinitat Nova (Tatjer 1995), los del LUB sobre la urbanización marginal (LUB 1974; Busquets 1999) que ponían en evidencia las carencias de sus barrios, hasta los centrados en las luchas vecinales (Fabre-Huertas 1997). Desde los referentes a las primeras fases del siglo XX (Font et al. 1993); a las compilaciones de la memoria gráfica de Nou Barris (Grau i Sánchez 2017) o las publicaciones e iniciativas de l’Arxiu de Roquetes-Nou Barris. Sobre la base de estas aportaciones, la investigación en curso propone la exploración de un amplio registro de fuentes primarias que permita adoptar una aproximación más relacional $\mathrm{y}$, en última instancia, que permita establecer puentes entre la construcción física y la construcción social de los barrios. Dos fuentes laboriosas y de carácter angular para la investigación, el vaciado de los padrones de 1960 y 1970 (no así los de 1940 y 1950) y la realización de entrevistas, se han visto retrasadas a causa de la pandemia. De modo que este artículo se plantea como un avance a completar en posteriores fases de la investigación.

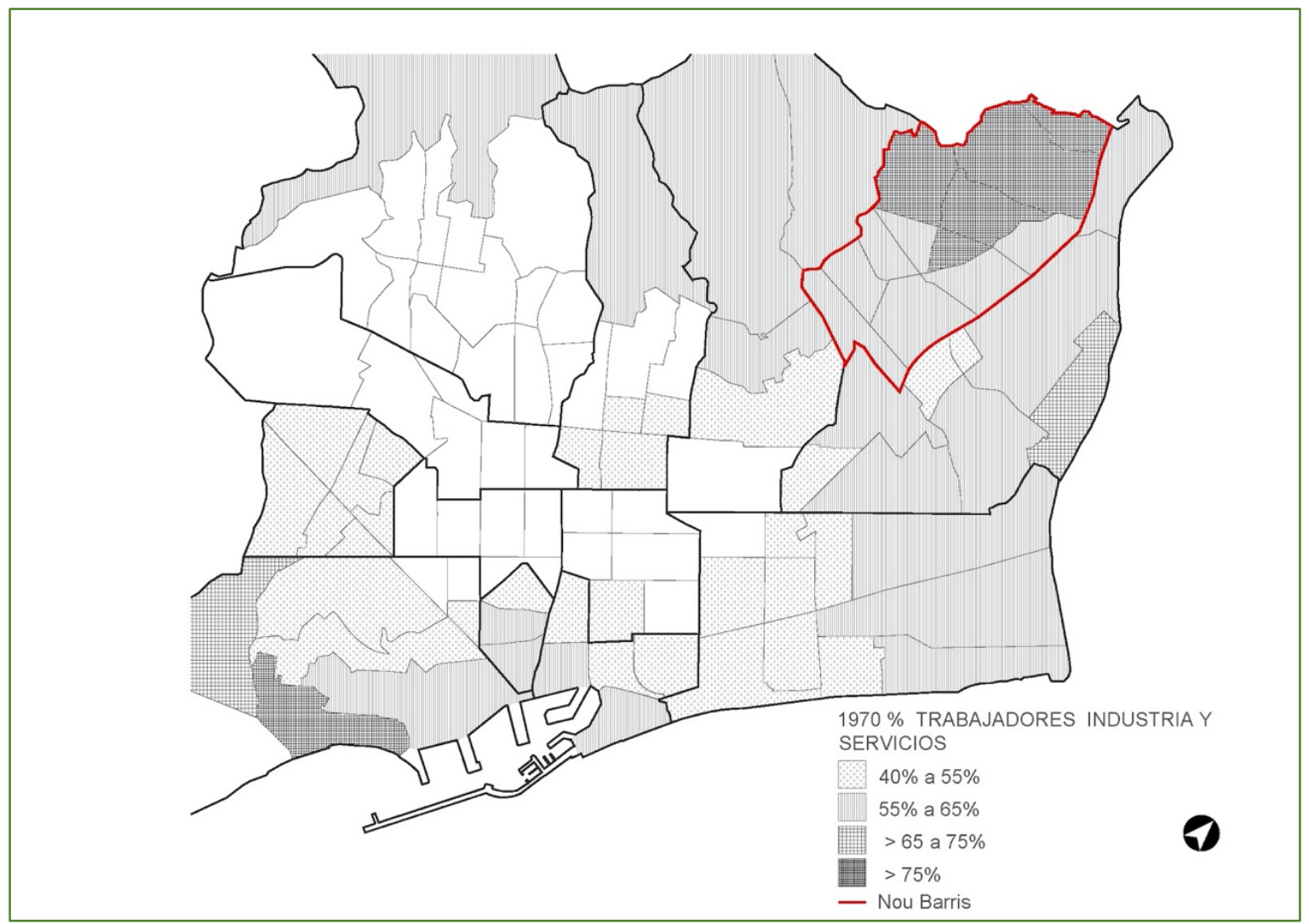

Figura 1

1a. División de los distritos de Barcelona vigente entre 1949 y 1983

1.b Población de Barcelona por distritos en 1950, 1960 y 1975.

Fuente: Elaboración pròpia sobre datos de Estadística Municipal

1c. Trabajadores y trabajadoras de la industria, servicios,comunicaciones y transportes en 1970.

Fuente: Elaboración propia sobre datos digitalizados del Padrón 1970. 
Para el trabajo empírico se han utilizado los resúmenes estadísticos anuales publicados por el Ayuntamiento de Barcelona, así como los datos digitalizados por secciones censales de los padrones de habitantes de 1970, 1975 y 1978, del censo de viviendas de 1970 y los referentes a la radicación de 1977, facilitados por el Departament d'Estadística i Difusió de Dades del Ayuntamiento de Barcelona. Se han completado con el vaciado sistemático de los datos del Catastro, cruzados con el vaciado de las fichas de licencias de obra particulares y de obra pública, ordenadas por calles, así como la documentación sobre polígonos y planes parciales, y la consulta de las licencias relevantes, en el Arxiu Municipal Contemporani. Esta documentación se ha completado con la que proporcionan otros archivos, como el de Roquetes-Nou Barris, Diocesano, la información cartográfica y fotográfica disponible, la procedente de la hemeroteca y otras fuentes secundarias.

Sobre estas bases el artículo trata de poner en evidencia cinco asuntos principales en el análisis de las periferias residenciales obreras. Primero, que estas no brotaron súbitamente durante el franquismo sobre una tabula rasa. Fueron esenciales las herencias (fundamentalmente de entreguerras), los procesos y sus tiempos. Segundo, que conviene diferenciar las etapas y, en lo que desde la perspectiva de la oferta se ha visto como un único gran ciclo de construcción entre 1954 y 1975, parece necesario distinguir la marcha y problemática de la década de 1950 de la posterior explosión constructiva de la etapa 'desarrollista', la de la auténtica transformación de las periferias y sus formas de habitar. Tercero, polígonos de vivienda, barrios de densificación y barrios de autoconstrucción, con sus tiempos, diferencias y contrastes, muestran el claro predominio de la densificación sobre los polígonos, confirmando así la importancia de las continuidades históricas.

En cuarto lugar, en lo que demasiado genéricamente llamamos "periferia", los grados de centralidad y accesibilidad permiten distinguir una corona exterior y una corona interior con dinámicas y características diferenciadas desde el punto de vista de la clase social, la propiedad de la vivienda y la dotación comercial y de infraestructuras. Finalmente, el artículo destaca el papel pionero de la vivienda en propiedad en Nou Barris y sugiere sus posibles implicaciones en la articulación de un potente movimiento vecinal que fue destacado protagonista de las luchas urbanas de los últimos años del franquismo.

\section{El crecimiento de Nou Barris y sus etapas, 1939 -1980: continuidades y fases}

La curva de la media móvil de incremento anual de viviendas en Nou Barris, basada en el catastro y las licencias, se mantiene significativamente plana en los años 1940 para dibujar después un gran ciclo largo de la edificación entre 1953 y 1978 (Figura 2). En esos veinticinco años intensísimos se construyeron 66.217 viviendas multiplicando por diez el parque de viviendas existente en 1950 (6.540 viviendas). La población septuplicó en el mismo período, pasando de los 31.000 habitantes, sólo un 2,4 \% de la ciudad de Barcelona, a más de 200.000 (218.498 en 1975), un 12,5\% del total barcelonés. Este intenso ciclo constructivo solo declinó por los efectos de la crisis de mediados de los setenta, con una caída abrupta de 
nuevas viviendas entre 1975-1980. Una primera etapa, la de los años cuarenta, quedaría pues marcada por el marasmo económico del período de la autarquía, el ínfimo crecimiento habitacional y las continuidades desde el punto de vista morfológico en el área de Nou Barris. Aunque, desde el punto de vista de la producción de viviendas, se podría considerar luego un único gran ciclo hasta la década de 1970, hay razones de peso para considerar la década de 1950 como una etapa diferenciada, y no sólo porque se dibujó muy claramente un intenso ciclo corto entre 1953 y 1957 . Si se considera desde el punto de vista de la demanda, el gráfico que compara las viviendas autorizadas con el aumento de habitantes por quinquenio en Barcelona marca una inflexión decisiva en torno a 1960 (Figura 3). Durante los años 1950 el crecimiento de la población (debido principalmente a la inmigración) superó con creces al de nuevas viviendas, con un grave empeoramiento de las condiciones del alojamiento. La situación sólo cambió con claridad en la década de 1960, cuando el crecimiento en la producción de viviendas superó radicalmente los incrementos poblacionales del municipio. La década de 1950 merece además una atención diferenciada por tratarse de un período de transición, de cambios en el marco institucional y económico en los que se implementa por primera vez una política de vivienda, y en la que se ponen las bases esenciales para la decisiva eclosión de la década siguiente. Fue efectivamente, entre 1960 y 1974, cuando se desplegó el largo y sostenido ciclo de intensísima actividad inmobiliaria que cambió de raíz el artefacto construido heredado, transformando radicalmente, como en tantas periferias de las grandes ciudades españolas, el paisaje residencial de Nou Barris.



Figura 2. La construcción residencial en Nou Barris, 1939-1980.

Fuente: Elaboración propia a partir de las licencias (AMCB) y datos del catastro. 


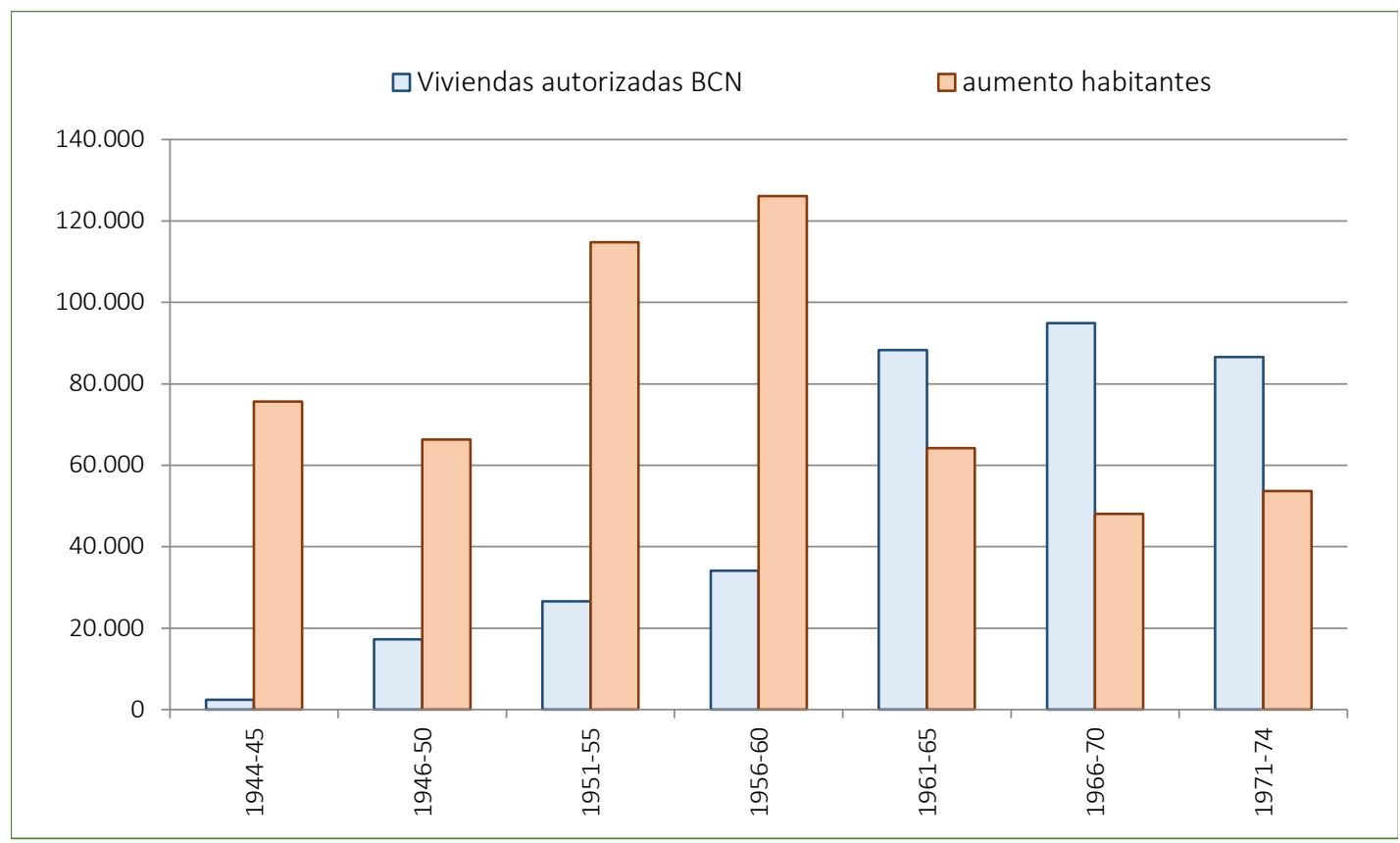

Figura 3. Incremento de viviendas y de habitantes por quinquenio en Barcelona, 1944-1974. Fuente: Elaboración propia a partir de los resúmenes anuales de Estadística Municipal

En la figura 4 se aprecian los desajustes de la curva de la edificación residencial en Nou Barris y la general de Barcelona (medida ésta con las autorizaciones de construcción de nuevas viviendas en la estadística municipal). En términos relativos, en los difíciles años cuarenta se autorizó una mayor proporción de nuevas viviendas en la ciudad en distritos periféricos como Nou Barris. En los años cincuenta en cambio despegó un ciclo residencial en Nou Barris mucho más fuerte que en la ciudad y se inició luego el más importante en 1957 con mayor ímpetu ascendente que el de la ciudad hasta el pico de 1964. Por contra, mientras la curva de Nou Barris tomaba desde entonces un perfil declinante, y especialmente en los primeros setenta, la curva barcelonesa alcanzaba sus cotas más altas.

Esta alternancia entre un crecimiento pionero en las coronas periféricas seguido después por uno de las más centrales es el ya observado en el ciclo largo de entreguerras: el ciclo corto del quinquenio 1921-1927 fue espectacular en las barriadas extremas y mucho menos acusado en la corona menos periférica, mientras que los ciclos cortos con máximos en 1930 y 1935 otorgaron un claro protagonismo a ésta (Oyón 2008, 39-53; Whitehand 1987).

\section{Las herencias de la situación de partida: Nou Barris 1939}

Las varias decenas de licencias para construir casitas de planta baja en la zona de Santa Eulàlia de Vilapicina, el auténtico despegue de todos estos barrios tuvo lugar justo al terminar la Primera Guerra Mundial. Fueron los años de la explosión de las segundas periferias, concentrada en un potentísimo ciclo de construcción residencial entre 1919 a 1926 con ecos en otros dos ciclos más modestos en torno a 1930 y a 1935 (Oyón 2008, 4753). En esos años de entreguerras se concedieron más de 1400 permisos para construir viviendas de nueva planta en el futuro Nou Barris. Tres cuartas partes se localizaron en la 
zona de Can Dragó, convertida sin duda en el área periférica más dinámica de Barcelona con más de la décima parte del total de permisos de obra de todo el cinturón suburbano. En 1930 el actual distrito contaba ya con 16.921 habitantes (10.812 en el barrio administrativo de Santa Eulàlia y 6.109 en el de Roquetes) y alcanzará los 23.100 al terminar la Guerra Civil, según nuestras estimaciones del Padrón de 1940Nou Barris del franquismo no nacieron de la nada. Si bien desde la agregación municipal de 1897 se habían concedido.

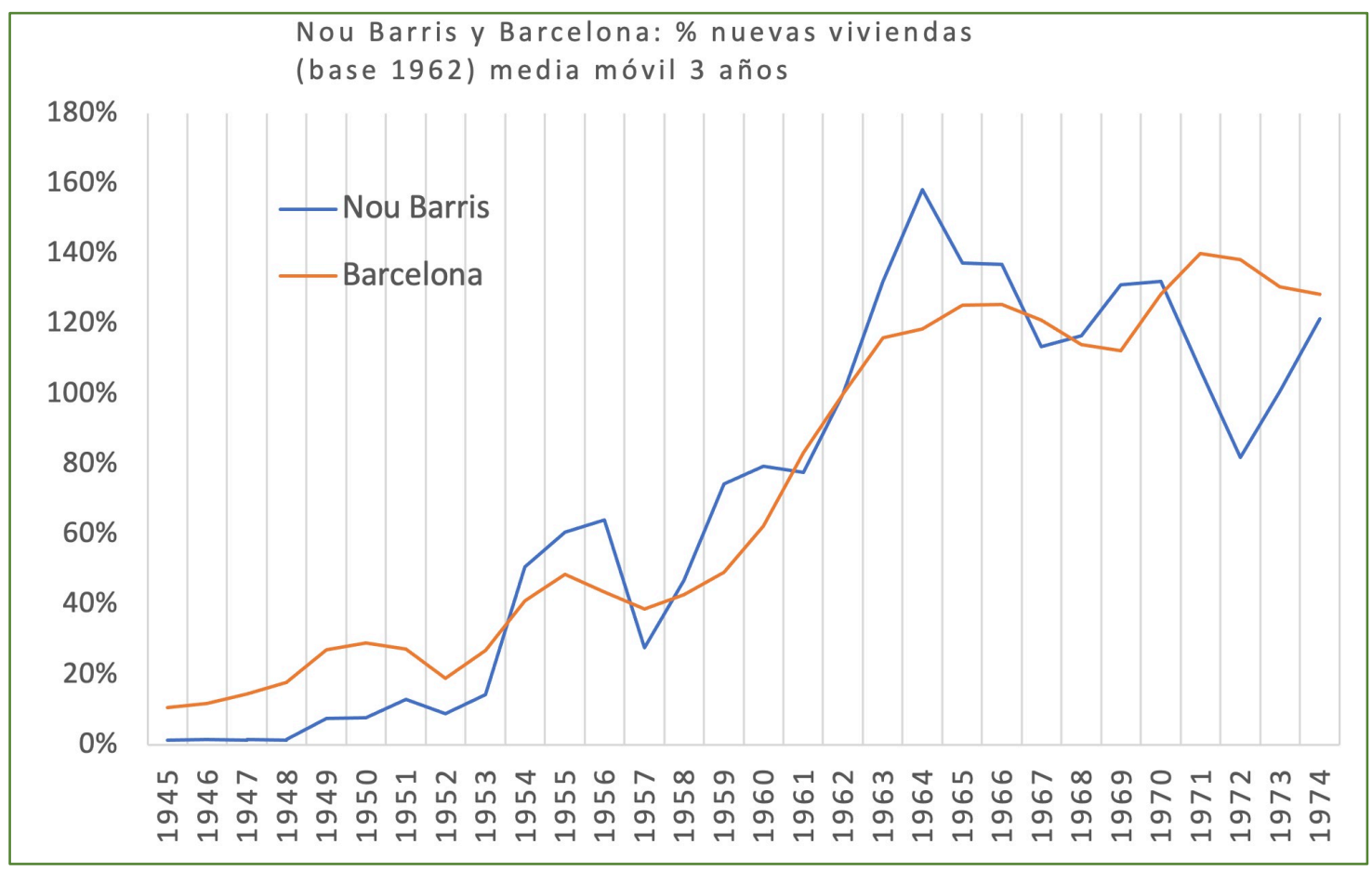

Figura 2. La construcción residencial en Nou Barris y Barcelona, 1945-1974.

Fuente: Elaboración propia a partir de las licencias (AMCB) y datos del catastro.

Esos años decisivos marcaron, en primer lugar, las localizaciones iniciales y la morfología de los barrios. Dibujaron el plano viario y las formas y tamaños de las parcelaciones donde los propietarios vendieron multitud de pequeños solares de no más de 100 o 150 metros cuadrados para edificar pequeñas casetes para alquilar (y en no pocos casos para residir en ella los compradores (Cordiviola, Monclús, García y Oyón 1993; Oyón y García 1998). Es así como en la zona de Can Dragó nacieron las nuevas barriadas de Prosperitat, Verdum, Roquetes, Charlot y Can Borrás. En posición todavía más alejada, se comenzaron también a construir casetes junto la actual zona de Trinitat Nova o en el pequeño enclave de la Guineueta, e incluso se construyeron algunas pequeñas torres y casetas en las lejanas Torre Baró y Vallbona. Crecieron también algunas parcelaciones anteriores en la zona de Porta. Aunque en el decenio anterior a la guerra el ritmo de construcción en el distrito decreció hasta las 400 licencias, en 1929 apareció en la ladera norte del Turó de la Peira la barriada de casas baratas Ramón Albó del Patronato Municipal de la Habitación. Con más de 700 viviendas aportó ella sólo cerca de dos terceras partes del total de viviendas construidas durante el decenio. Esa alternancia entre procesos de construcción residencial horizontal muy menuda, que van formando tejido de manera sedimentaria y acumulativa sobre 
trazados previos, y procesos más masivos y concentrados en el tiempo en terreno virgen, será la segunda de las herencias históricas del paisaje residencial del distrito en el franquismo.

La tercera de las herencias históricas que interesa retener de esos años formativos de entreguerras es la de las diferencias socio-espaciales entre la parte norte del distrito, el barrio administrativo de Roquetes, y la parte sur, el de Santa Eulàlia. A pesar del carácter masivamente obrero de las dos áreas, la parte norte era abrumadoramente de cabezas de hogar obreros no cualificados (un 93\%) mientras que en la parte sur representaban el 75\% (la media de la ciudad era de poco más del 50\%). Esas ligeras diferencias socio-laborales iban acompañadas de una mayor presencia al norte de los cabezas de hogar no catalanes llegados después de 1910 con gran relevancia de aragoneses y sobre todo murcianos. El parque de vivienda, que es lo que nos interesa, era de composición todavía más diferenciada. Dentro de una dominancia compartida de las casetas de bajos de pequeña dimensión (entre 40 y $70 \mathrm{~m}^{2}$ útiles) que definían el paisaje urbano, en el norte apenas existían viviendas de pisos mientras que llegaban éstas en el sur a cerca del $30 \%$ del total. Formas de vivienda precaria, como las barracas o los pasillos, que suponían más del 6\% de las viviendas de la parte norte eran desconocidas en el sur (ocurría lo mismo con las pequeñas torretes). La propiedad de la vivienda era minoritaria en el distrito, pero representaba una de cada cuatro viviendas, el mayor porcentaje de toda Barcelona. Será otro de los elementos de continuidad con los años del franquismo, como veremos. No obstante, variaba también de un 32\% de hogares en propiedad en el norte a un $20 \%$ en el sur. El rasgo más relevante de diferenciación lo constituía sin embargo la mayor presencia de algunos atributos de centralidad en el sur: mayor cantidad y variedad del comercio; algunos talleres e industrias muy cercanos a los lugares de residencia; $y$, sobre todo, disponibilidad de un transporte tranviario barato y eficaz, lo que significaba mejores conexiones con el resto de la ciudad. En vísperas de la Guerra Civil la parte meridional era, en muchos sentidos, un área menos periférica que la parte norte del distrito.

\section{Continuidad morfológica, autoconstrucción y precariedad habitacional, 1939-1950}

La dura década de posguerra mantuvo el carácter obrero y mayoritariamente inmigrante del barrio (un 83\% de población obrera y más de la mitad de cabezas de hogar venidos de fuera de Cataluña), y una clarísima continuidad con el urbanismo horizontal típico de las periferias de entreguerras, de acuerdo con el vaciado de las fichas de licencias en una serie de calles seleccionadas por barrios. Morfológicamente, los barrios de 1950 seguían siendo los mismos de antes de la guerra, sólo que más extensos (figura 5).

La general atonía en la provisión de vivienda fue menor en Nou Barris que en el conjunto de Barcelona. En la década se consiguió casi igualar la apreciable dinámica constructiva de 1927 a 1936, sin contar las viviendas autoconstruidas y las barracas: cerca de 2.000 unidades. Según el padrón de 1950 la población creció en los años cuarenta un destacable $34 \%$, una tasa que doblaba casi la media de la ciudad. 
Las nuevas viviendas levantadas durante los cuarenta fueron casi todas unifamiliares de planta baja, en algún caso de planta baja y piso. Fueron escasas las adiciones de pisos y las sustituciones por nuevos edificios de viviendas en altura. Éstos solo llegaban al 15\% y seguían mayoritariamente situados en los barrios más centrales del sur (82\%). Pero la forma de crecimiento dominante siguió siendo por extensión. Más de dos terceras partes de las nuevas viviendas se continuaron edificando en los barrios de casitas bajas de la parte norte más periférica del distrito, Prosperidad, Verdum, Roquetes Baixes, y los nuevos barrios de autoconstrucción. El vaciado del Padrón de 1950 confirma que un 81\% de todas las viviendas eran casitas de bajos.

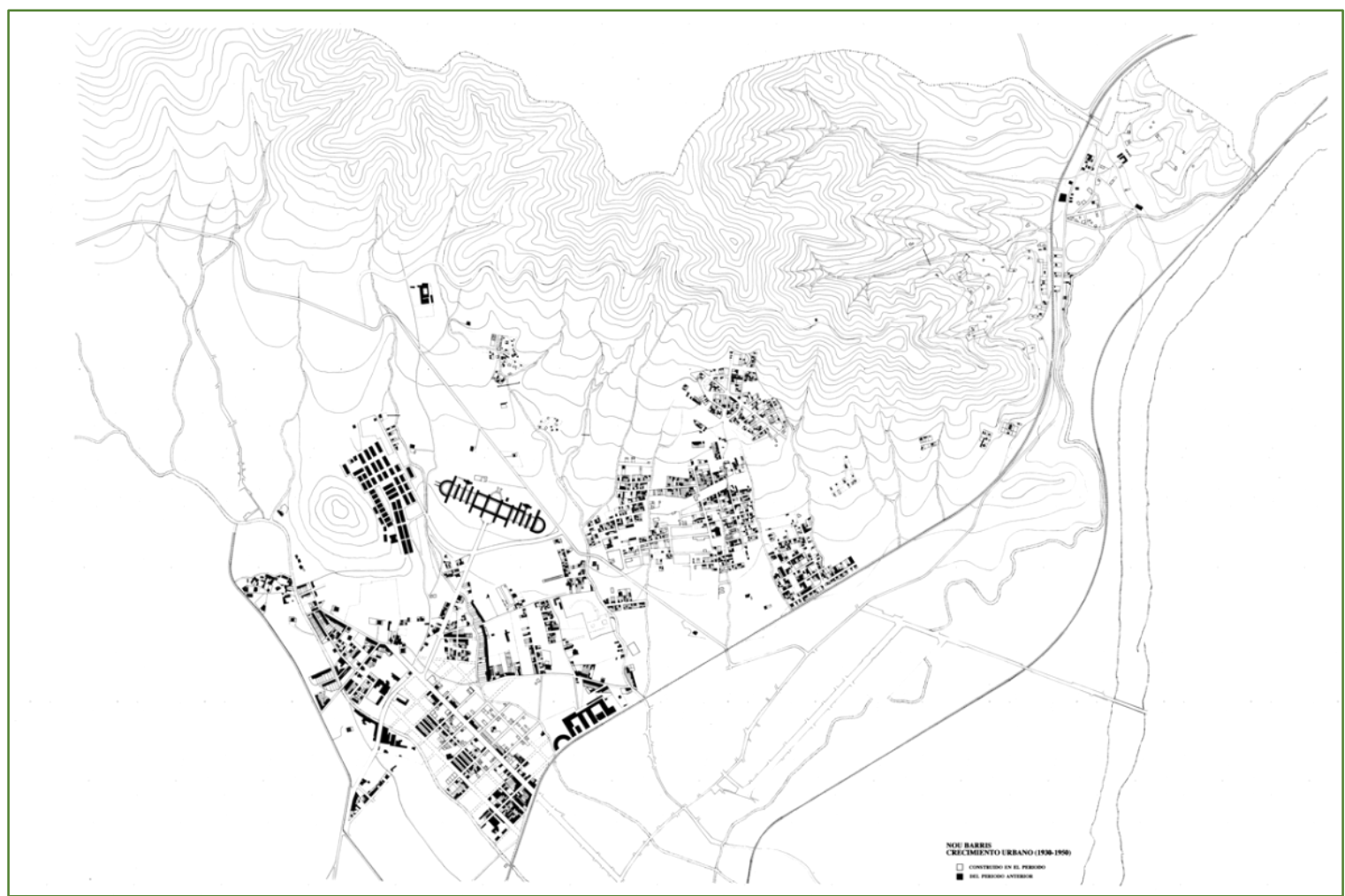

Figura 3. Nou Barris, 1930-1950. Continuidad morfológica y fusión de los primeros asentamientos Fuente: Treball de precatalogació del districte de Nou Barris realizado en 1992 por el equipo coordinado por Antonio Font (A. Cordiviola, C. Garcia, F.J. Monclús, N. Oliver y J.L. Oyón). Trabajo inédito.

Como en el resto de periferias obreras barcelonesas, lo auténticamente nuevo en Nou Barris durante esa década fue que, como consecuencia del espectacular retraimiento de la oferta (la población de la ciudad creció casi el doble que el parque de viviendas), se dispararon las formas del habitar más o menos precarias, como la autoconstrucción, el barraquismo y el hacinamiento habitacional. Parcelaciones donde en los años de entreguerras se habían concedido licencias de obras para construir casetes o modestas torretes quedaron fuera de ordenación. Los propietarios vendieron mediante contratos privados, pequeños lotes a los futuros residentes que, incapaces de acceder al delgadísimo mercado de la vivienda comercial o estatal, los adquirían habitualmente a plazos. Poco a poco y de forma flexible construyeron al menos 300 viviendas en esas barriadas más tarde 
conocidas como coreas: Torre Baró, Vallbona, Roquetes Altes y la Guineueta Vella. Estos procesos de autoconstrucción, representaron un $17 \%$ de toda la vivienda construida en el área de Nou Barris. Fue el inicio de un proceso que alcanzó su máximo impulso en las dos décadas siguientes.

Muestra del claro empeoramiento de la condición habitacional fue el rebrote del barraquismo. Si nos atenemos a las cifras censales, parece que el centenar de barracas de 1930 había descendido a una veintena durante los años treinta. En la primera década del franquismo se registra un repunte hasta llegar a unas 200 en 1950, más de un 9\% de toda la nueva vivienda creada en el distrito. El repunte fue semejante al experimentado en toda ciudad, donde el porcentaje de barracas dobló su tasa en esa década: del 1,7\% al 3,2\%.

Otro fenómeno decisivo del período fue la cohabitación. Según datos del padrón trabajados por Borja Iglesias en su tesis en curso, afectaba a la mitad de las familias trabajadoras de Barcelona en 1950. En los distritos del centro histórico fue especialmente llamativo, pero los distritos periféricos tampoco fueron ajenos al fenómeno. En los distritos noveno y décimo, que eran ya en 1950 los de mayor tasa de hogares obreros de la ciudad, la proporción de viviendas donde se cohabitaba igualaba casi a la de los viejos distritos segundo y quinto. Según el padrón de 1950, solo un 41,2 \% de las familias de Nou Barris residían en sus viviendas como familias nucleares estrictas. Un $41 \%$ de las familias corresidía con otras (habitualmente con un vínculo de parentesco, un 33,1\%; otro 17\% lo componían familias extensas). Todo ello resultaba en una alta cifra de ocupación habitacional, que, si no alcanzaba las tasas del centro histórico, sí resultaba apreciable: 4,7 habitantes por vivienda. Recién acabada la guerra la familia nuclear aún dominaba en estos barrios: dos de cada tres familias propietarias, tanto las obreras como las no obreras, eran familias nucleares estrictas y apenas existía la cohabitación con otros núcleos familiares. Terminada la década, la situación se había invertido. Sólo una de cada tres familias propietarias residía como familia nuclear estricta y más de la mitad de ellas cohabitaban con otros núcleos familiares, por lo general con una familia con vínculos de parentesco directo, doblándose en este caso la tasa de hacinamiento de la vivienda hasta más de seis habitantes por vivienda.

\section{El problema de la vivienda y la emergencia del suburbio, 1950-1960}

A pesar de la fuerte inmigración a las grandes ciudades y la gravísima escasez de alojamiento, hasta la década de 1950 el Estado se desentendió totalmente del problema de la provisión de viviendas para las clases populares. Era misión del Ministerio de Trabajo que supeditaba la política de vivienda, activar la economía y mitigar el paro. A pesar del evidente fracaso de la política autárquica, la pasividad se mantuvo hasta el boicot a los tranvías de 1951 en Barcelona y al subsiguiente cambio de Gobierno, más favorable a la liberalización económica. En 1952 desapareció oficialmente el racionamiento, y es justamente en esos años cuando se empieza a reconocer el problema de la vivienda como "primer problema nacional".

Ese fue el contexto de la aprobación del Plan de Ordenación de Barcelona y su zona de influencia de 1953, el llamado Plan Comarcal de Barcelona, con el objetivo de ordenar el crecimiento y procurar la oferta necesaria de suelo para una auténtica política de la vivienda. Josep Soteras, autor del plan, veía en Nou Barris un espacio de oportunidad. En su propuesta 
de Plan Parcial de Ordenación de Roquetes de 7 de noviembre de 1953 manifestaba: “...debido a estar esta zona edificada solo en parte y aún con grandes sectores de edificación nula, es fácil, afectando solamente pocas edificaciones (la inmensa mayoría de ellas de planta baja y de construcción sencilla), obtener una ordenación del barrio y una urbanización en consonancia con el papel que en un próximo futuro deberá desempeñar las Roquetas en relación con los núcleos adyacentes de Trinidad y Verdún...” Usos del suelo y ordenanzas fijaron techos de edificabilidad muy determinantes en los procesos de densificación posteriores y dejaron áreas, construidas en parte, fuera de ordenación o afectadas por las nuevas vías. En paralelo, arrancaban con mucha fuerza en Nou Barris los polígonos de vivienda.

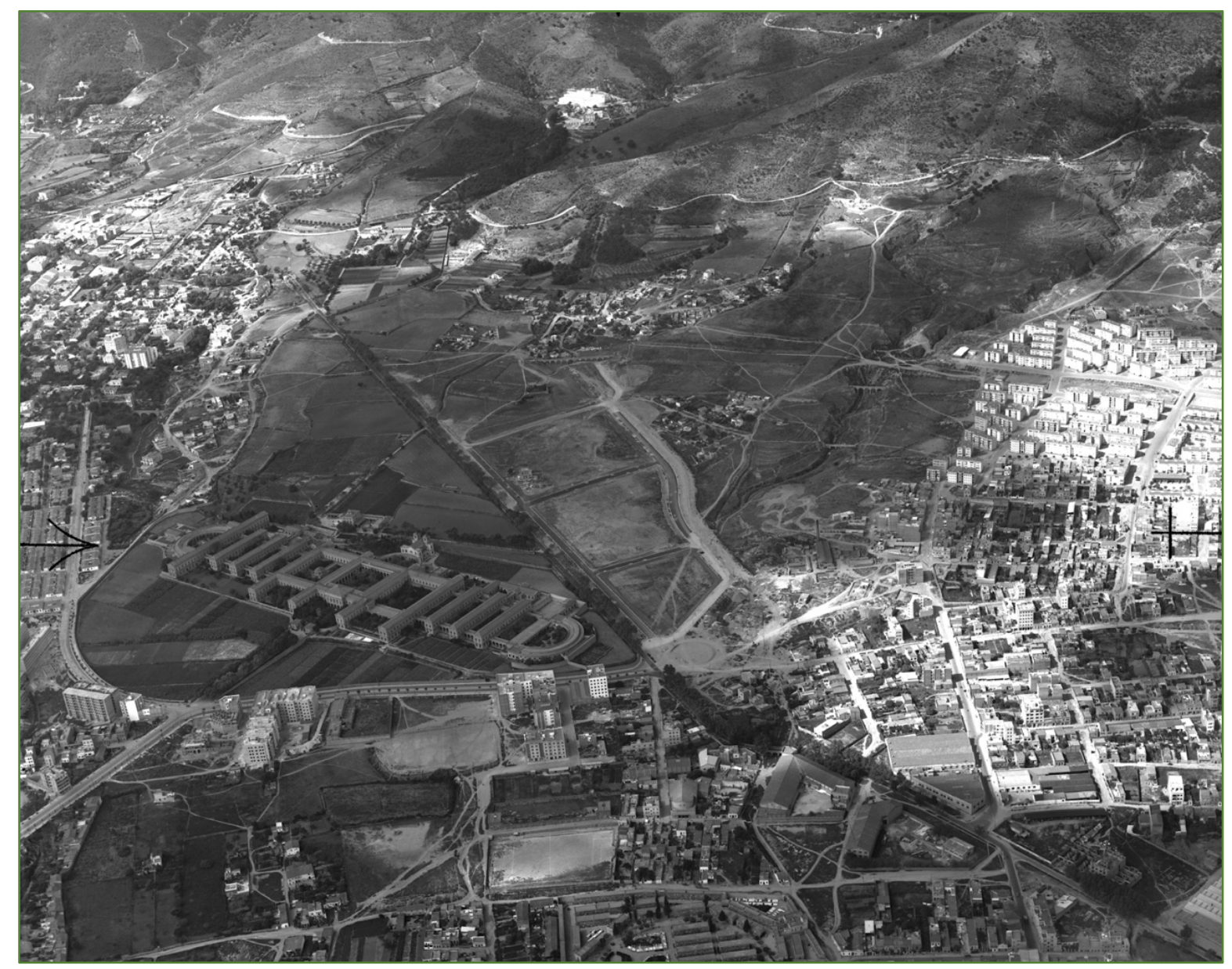

Figura 4. Vista de Nou Barris, 1959

Fuente: Fondo TAF (Trabajos Aéreos y Fotogramétricos), Arxiu Nacional de Catalunya

A partir de 1954, la nueva Ley de Viviendas de Renta Limitada inscrita en el II Plan de Vivienda redefinía el régimen de protección oficial de promoción privada y ofrecía exenciones, bonificaciones fiscales, suministro prioritario de materiales, subvenciones y créditos (Tafunell 1989, 224-230; Candela 2019). En los barrios de la zona sur, como Vilapicina/Fabra i Puig y de Porta, impulsados ya por los polígonos de Torre LLobeta y Turó de la Peira, se aceleraron entonces considerablemente los procesos de densificación (sólo 
tímidamente apuntados antes). Este mayor crecimiento de los barrios del sur se reequilibró al norte con la inauguración de las distintas fases del polígono de la Trinitat Nova, del de Verdum de la Obra Sindical del Hogar y de las casas del Gobernador (y en menor medida la creación de nuevas viviendas en las áreas de autoconstrucción más septentrionales) (figura 6). Una década pues de brusco despertar inmobiliario e incremento poblacional en contraste a la relativa atonía de la década precedente. El crecimiento habitacional fue mayor en la década siguiente, pero los cincuenta concentraron las mayores tasas de incremento quinquenal de todo el período franquista.

A finales de los años cincuenta, emergió con fuerza la problemática de estas periferias. En Barcelona en 1957 se celebró la Semana del Suburbio (Duocastella 1957) y en el caso de Nou Barris un informe elaborado en 1958 por los párrocos de Santa Engracia de Prosperidad y de San Sebastián de Roquetes y Verdum, a instancias de la Secretaría de la Cámara del Obispado, constataba la insostenible situación de aquellos barrios extremos. Las grandes distancias y las dificultades de los caminos hacían a menudo imposible la asistencia a misa, no existía el menor contacto con el sacerdote y todo ello motivaba la ruptura total e incluso una abierta hostilidad hacia las respectivas parroquias. El informe iba acompañado de un reportaje fotográfico realizado por J. M. Juncà de estos nuevos barrios, que valoraban como agrupaciones humanas auténticas que demandaban la creación de cuatro nuevas parroquias (Juncà y Puga 1958).

En paralelo, la remodelación del gobierno de 1957 no sólo significó un paso decisivo hacia la liberalización económica sino también la creación del Ministerio de la Vivienda, impulsor a través de los planes de urgencia de grandes operaciones de vivienda masiva. En el caso de Nou Barris, el Plan de Urgencia Social para Barcelona de 1958 no solo originó los polígonos de Guineueta y Porta; permitió también inversiones menos visibles como la construcción de colectores, indispensables en la parte norte del distrito que prácticamente carecía de alcantarillado. Por otra parte, desde la congelación de las rentas de alquiler de 1946, había crecido rápidamente en las mayores ciudades españolas la tenencia en propiedad horizontal sin un marco legal adecuado que presentaba muchos problemas especialmente para las operaciones de compraventa. Solo en 1960 se aprobará la esperada Ley de la Propiedad Horizontal que regulaba esta forma de tenencia de la vivienda y ofrecía mayores garantías a promotores y compradores.

\section{Iniciativa privada el impulso de los barrios del norte, 1960-1975}

Con estas bases y aprovechando el impulso desarrollista que siguió al Plan de Estabilización de 1959 y a las ayudas internacionales, la década siguiente fue la más decisiva en la creación de nueva vivienda y en la revolución del paisaje residencial de las periferias obreras (figuras 7, 12 y 15). A las grandes operaciones de vivienda masiva se sumará una creciente contribución de la promoción privada, con el rápido progreso de la propiedad horizontal y el impulso determinante a los procesos de densificación. Fue también partir de estas fechas cuando, de forma lenta pero gradual, irá mejorando la dotación de servicios y el equipamiento de los hogares.

Aunque las barriadas de Vilapicina/Fabra i Puig y Porta siguieron experimentando importantes procesos de densificación residencial y se ocuparon las viviendas de los 
polígonos de Porta y primera fase de la gran operación de Can Ensenya, fueron los barrios de densificación del norte, especialmente Prosperitat y en menor medida Verdum y Roquetes Baixes los de mayor crecimiento. También se inauguraron los polígonos de Guineueta, primero, y de Ciutat Meridiana y primera fase de Canyelles después. En la década de 1970, nuevamente la densificación de los barrios del sur superó la de los barrios del norte, a lo que se vino a sumar la continuación del polígono de Can Ensenya.

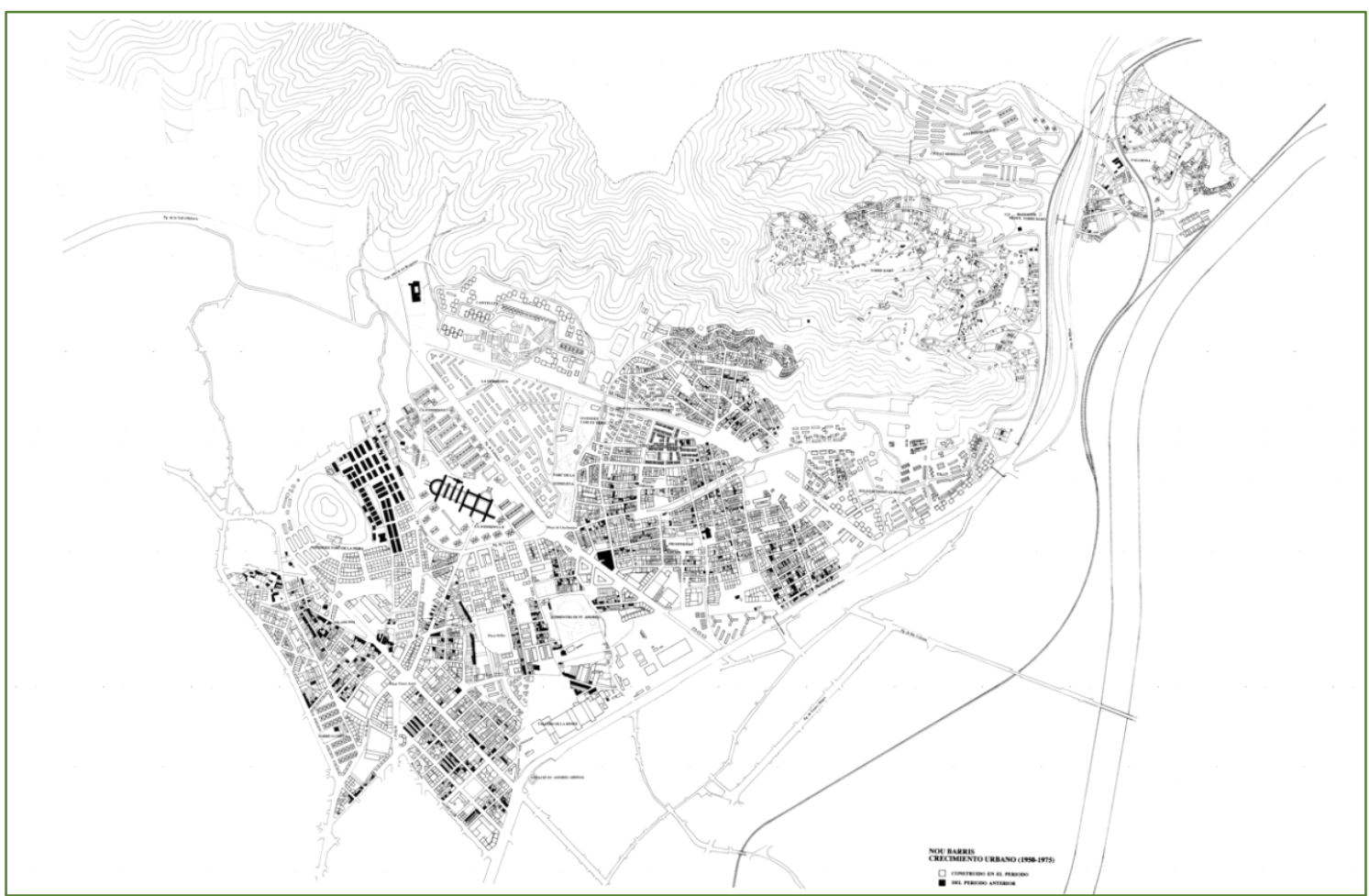

Figura 5. La revolución del paisaje residencial: Nou Barris, 1950-1975. Polígonos y densificación y desaparición de la ciudad horizontal.

Fuente: Treball de precatalogació del districte de Nou Barris realizado en 1992 por el equipo coordinado por Antonio Font (A. Cordiviola, C. Garcia, F.J. Monclús, N. Oliver y J.L. Oyón. Trabajo inédito).

En su conjunto, pues, la dinámica de la construcción residencial dentro del propio distrito reflejó en Nou Barris ese crecimiento alternante de fuera a dentro o si se quiere de la extensión periférica al relleno central (filling-in) posterior observado anteriormente a la escala del municipio. Se confirman así las lógicas temporales de un sensible movimiento pendular corona exterior-corona interior, norte-sur (o de extensión periférica-colmatación central) más o menos acentuados o atenuados.

Como puede apreciarse en la Figura 8, las curvas de los sectores norte y sur tienen formas distintas. La del sector norte, o corona periférica exterior, presenta una forma típica "en pico" con máximos de hasta 3.000 viviendas en el primer lustro de los sesenta. La del sector sur presenta una forma "en meseta" con un primer escalón en los cincuenta y una serie de colinas que rara vez superan las 1500 viviendas hasta mediados de los setenta. Mientras la primera se ajusta mucho mejor a la dinámica general de Nou Barris, la segunda la dibuja de manera mucho más laxa. Si la primera curva ofrece la imagen de explosividad típica de un boom muy intenso de la construcción, la segunda dibuja una dinámica también intensa, pero 
no tan violentamente cíclica. Es especialmente llamativo el desajuste de las dos curvas en la década de los sesenta, la realmente trascendental en el cambio del paisaje residencial del distrito y la del crecimiento más intenso de los barrios más periféricos del distrito. Numerosos factores explican estas alternancias corona exterior-corona interior dentro del distrito: mercado del suelo, planeamiento, nivel de equipamientos y servicios, dotación de transporte y diferente composición social.

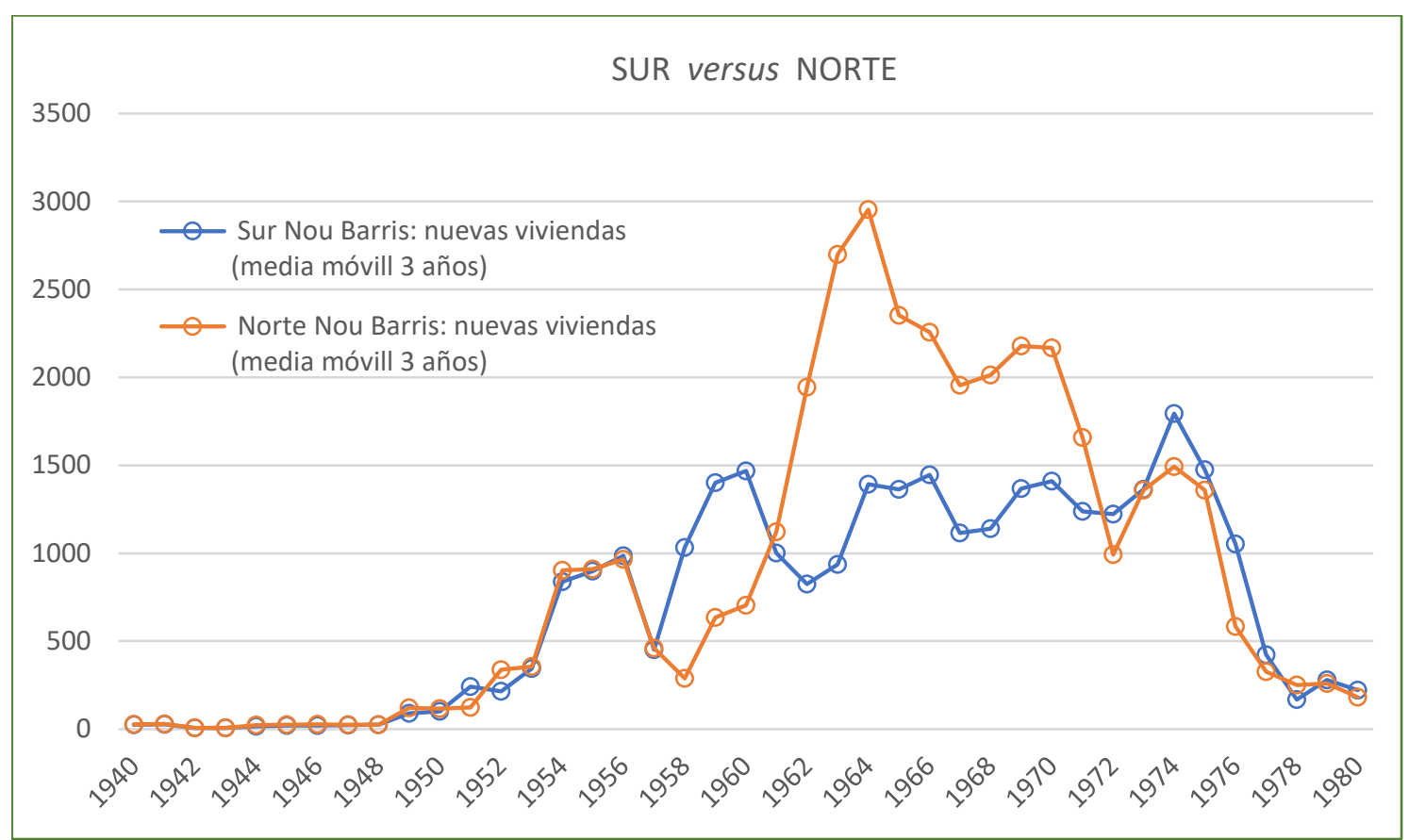

Figura 6. La construcción residencial comparada de las zonas norte y sur de Nou Barris, 1939-1980.

Fuente: Elaboración propia a partir de las licencias (AMC) y datos del catastro.

\section{Polígonos, autoconstrucción y densificación: collage versus palimpsesto}

Nou Barris es un ejemplo prototípico de la irrupción de los polígonos de vivienda masiva propia del crecimiento en periferia. Hay al menos catorce polígonos de momentos, dimensiones y características diversas (figura 9). Aun así, en su crecimiento predomina la densificación de tejidos residenciales previamente establecidos, por sustitución del caserío preexistente de baja altura y viviendas unifamiliares por edificaciones plurifamiliares entre medianeras de cuatro, cinco y hasta seis pisos: frente a las 25.521 viviendas catastradas en polígonos $(37,4 \%)$, se contabilizan 42.731 en barrios de densificación $(62,6 \%)$.

En la figura 10 puede verse la relevancia de los barrios iniciados como parcelaciones de casitas bajas en los años veinte y luego densificados frente a los otros dos procesos característicos de Nou Barris: la autoconstrucción y los polígonos. En aquellas barriadas se ubicó más del 60\% de todo el enorme stock de nueva vivienda habitada en los años del franquismo. La vivienda creció con fuerza en los barrios de densificación desde los cincuenta, pero alcanzó sus máximos en la década de los sesenta. Como muestra la figura 11, es muy 
significativo que la curva de los barrios de densificación se corresponde mucho mejor que la de los polígonos con la curva general del distrito en el gran ciclo de la vivienda que va de finales de los cincuenta a principios de los setenta, el más decisivo sin duda de todo el franquismo. Es la prueba de la trascendencia de este tipo de tejidos residenciales. A manera de palimpsesto, en este nuevo paisaje residencial se fueron poco a poco transformando los tejidos urbanos heredados de manera capilar y sedimentaria.

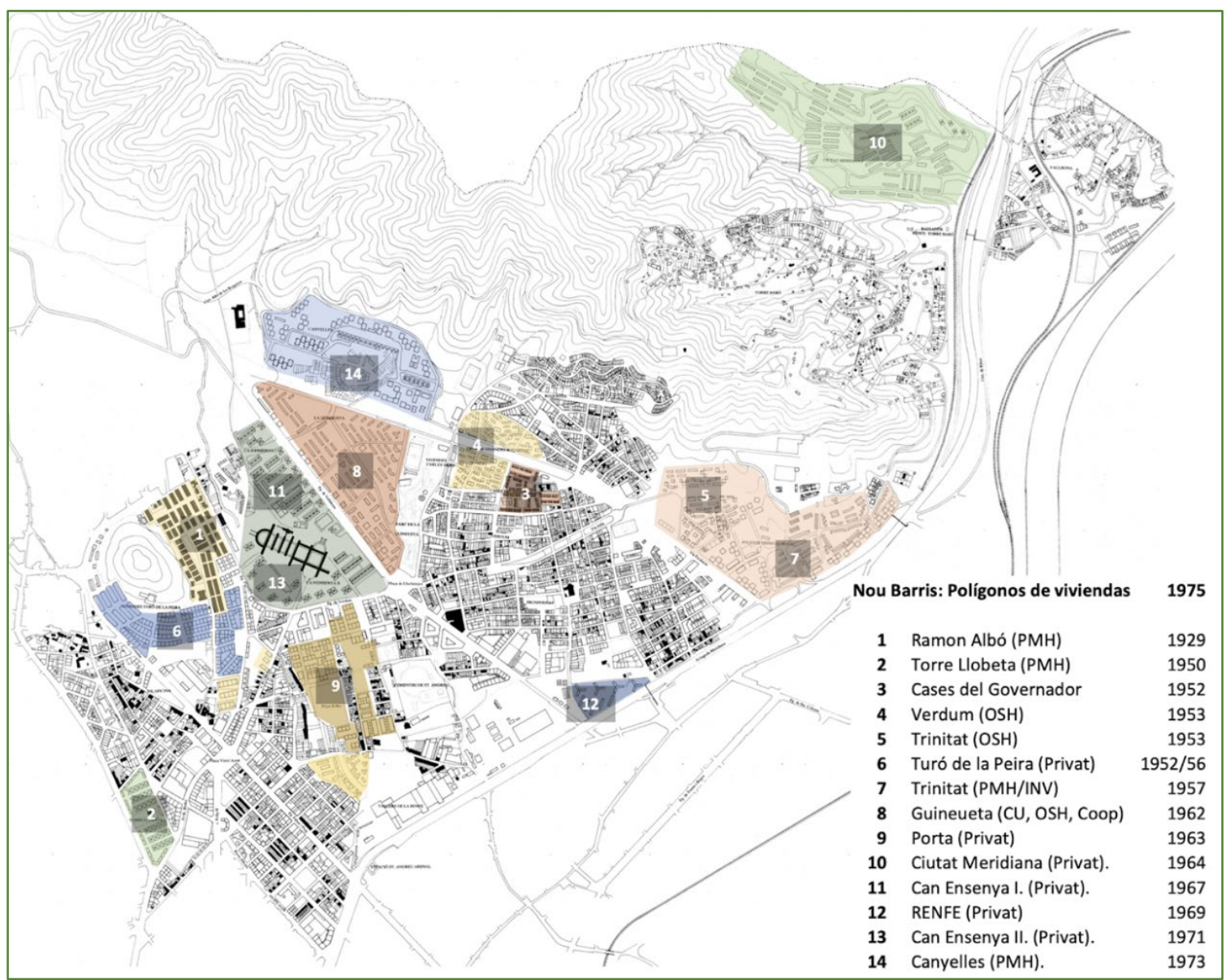

Figura 7. Los polígonos de Nou Barris, 1939-1980.

Fuente: Elaboración propia a partir del plano de 1950 a 1975 del Treball de precatalogació del districte de Nou Barris realizado en 1992 por el equipo coordinado por Antonio Font (A. Cordiviola, C. Garcia, F.J. Monclús, N. Oliver y J.L. Oyón). Trabajo inédito.

Los polígonos comenzaron a ser relevantes antes que la densificación. En efecto, el súbito despegue de la vivienda de Nou Barris en el primer lustro de los cincuenta se debió en gran medida a la inauguración de las operaciones de Torre Llobeta, Turó de la Peira, casas del Gobernador, grupos de Verdum-Roquetes y primeros tramos de Trinitat Nova, todas ellas rondando o superando los mil alojamientos. Con cerca de 9.000 nuevas viviendas durante los cincuenta, ese primer ciclo residencial de polígonos definió por sí solo la curva entera de la construcción del distrito (Figura 11). Algunos de esos polígonos de primera generación como Torre Llobeta y Turó de la Peira adquirieron densidades altas, y serán los polígonos de 
bloques abiertos de la segunda generación los que ofrezcan densidades claramente mucho más bajas y representativas de la forma polígono en el distrito.

En la década decisiva de los sesenta, y a pesar de la aportación de grandes operaciones de vivienda masiva como la Guineueta (figura 12) y Ciutat Meridiana, la curva de vivienda en polígonos no definió ya la curva general de la construcción del distrito. Sólo a principios de los setenta con la aportación de la segunda fase de Can Ensenya y Ciutat Meridiana y Canyellas volvieron otra vez los polígonos a manifestar un claro (y breve) protagonismo en la definición de la curva general del distrito.

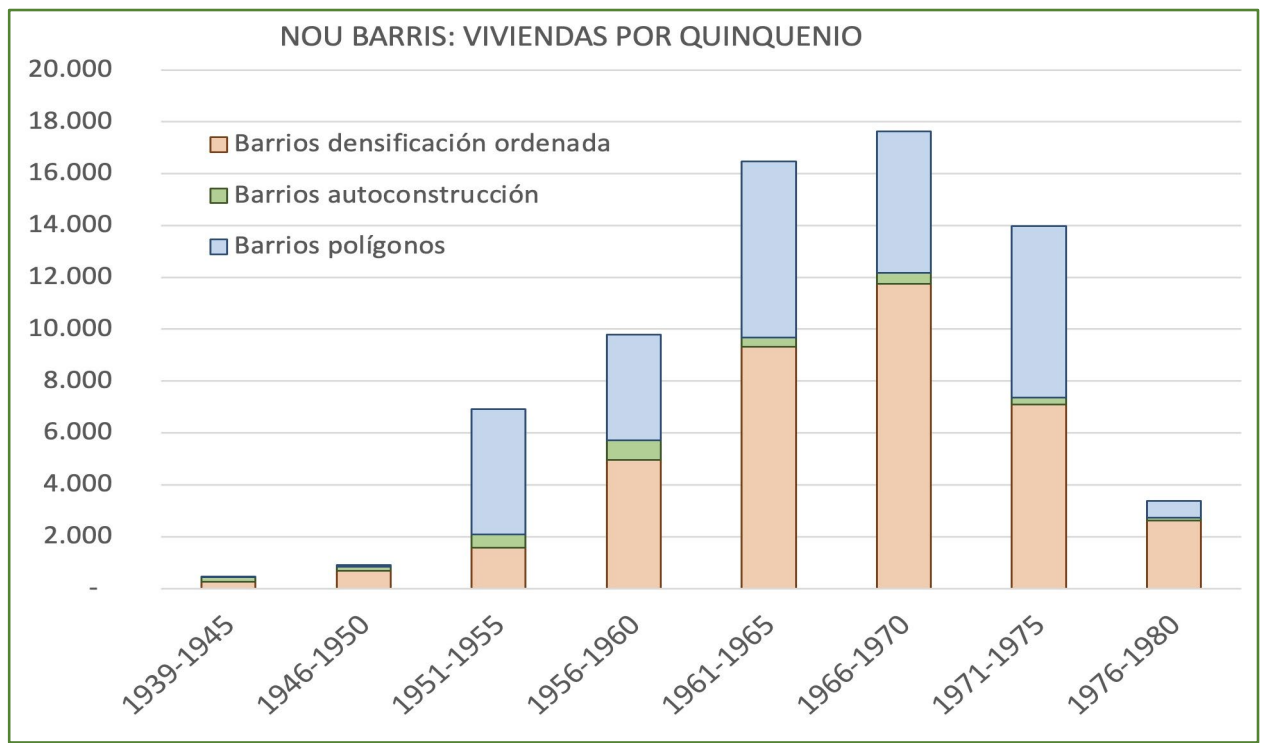

Figura 8. Autoconstrucción, polígonos y barrios de densificación, 1939-1980.

Fuente: Elaboración propia a partir de las licencias (AMC) y datos del catastro.

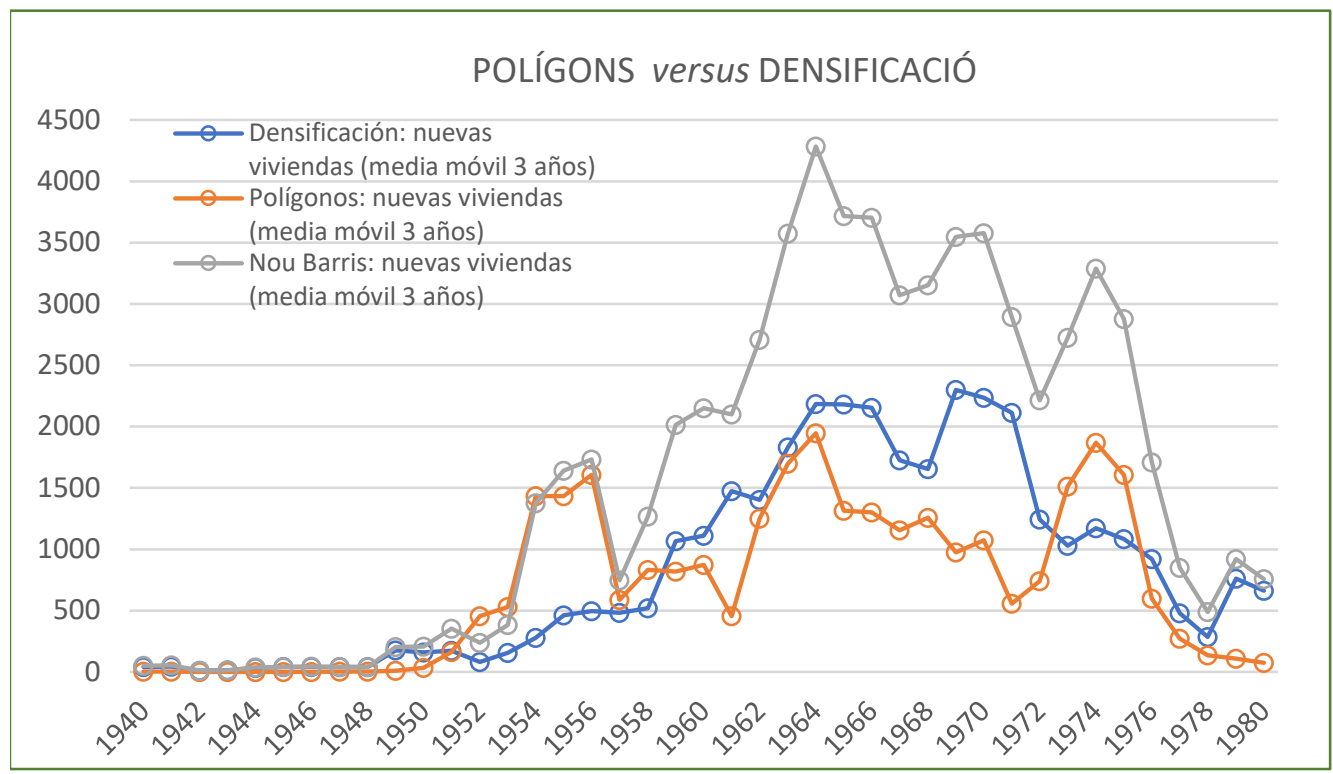

Figura 9. La dinámica contrastada de polígonos y procesos de densificación, 1939-1980. Fuente: Elaboración propia a partir de las licencias (AMCB) y datos del catastro. 
A pesar de que sus cifras crecieron hasta finales de los cincuenta, la vivienda autoconstruida sólo tuvo una presencia relativa destacable en la década de los cuarenta. Muchas veces, la nueva vivienda edificada después de 1960 en esas barriadas fuera de la legalidad se dio en procesos de densificación interna dentro de la propia parcela, procesos que se prolongaron hasta el final de la dictadura. En comparación con las de los polígonos y los barrios densificados, su curva general fue extremadamente plana, decreciendo desde 1960.

\section{De la ciudad horizontal a la vertical}

Al margen de la súbita verticalización de los nuevos polígonos, el análisis de las licencias de obras muestra que los procesos de densificación fueron más graduales. Pasaron por etapas preparatorias, primero en forma de adiciones de pisos, después en forma de derribos del caserío menudo heredado en la posguerra de planta baja y planta baja y piso, y sustitución por casas plurifamiliares entre medianeras. Como puede apreciarse en la figura 13, la década de los cuarenta apenas alteró la ciudad horizontal de casitas de bajos. Las licencias solicitadas fueron en su mayoría de casas unifamiliares de planta baja o de planta baja y piso. Apenas hubo adiciones de piso o levantes sobre la edificación unifamiliar previamente existente; y, aunque empezó el proceso de edificación de casas de pisos en solares libres o derribando edificación existente, su dinámica fue tímida y representó sólo una de cada cuatro nuevas viviendas. Lo nuevo en la década de los cincuenta fue el incremento de las adiciones de piso, que ascendieron a cerca de un tercio de toda la nueva vivienda.

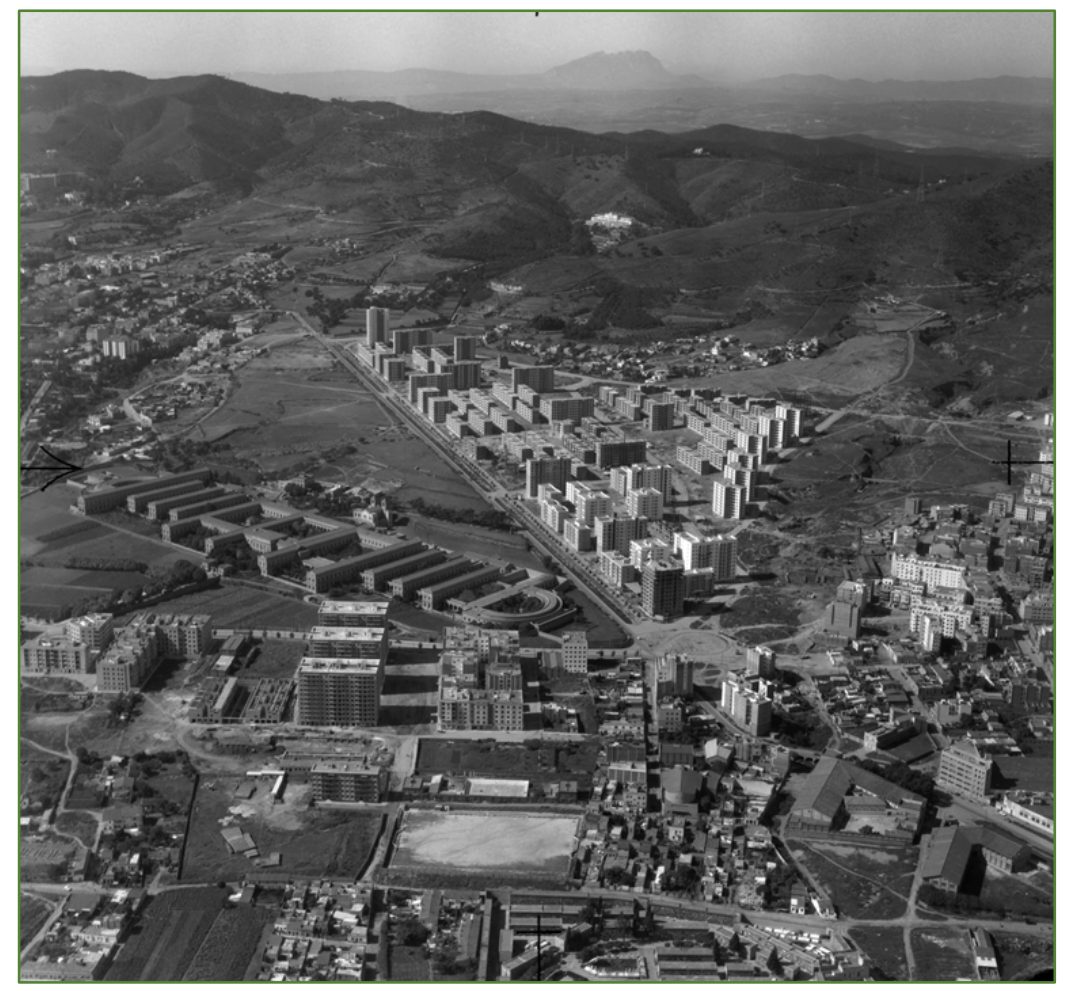

Figura 12. Vista de Nou Barris (Polígono La Guineueta en el centro) en 1963. Fuente: Fondo TAF (Trabajos Aéreos y Fotogramétricos), Arxiu Nacional de Catalunya 
Sólo en la década de los sesenta comenzará a cambiar radicalmente el paisaje heredado. La edificación unifamiliar de tamaño menudo dejó prácticamente de construirse y sólo sobrevivió un escaso porcentaje de adiciones $(12,5 \%)$. En la década final de los setenta, tanto la edificación menuda unifamiliar como las adiciones se convirtieron ya en meramente residuales.

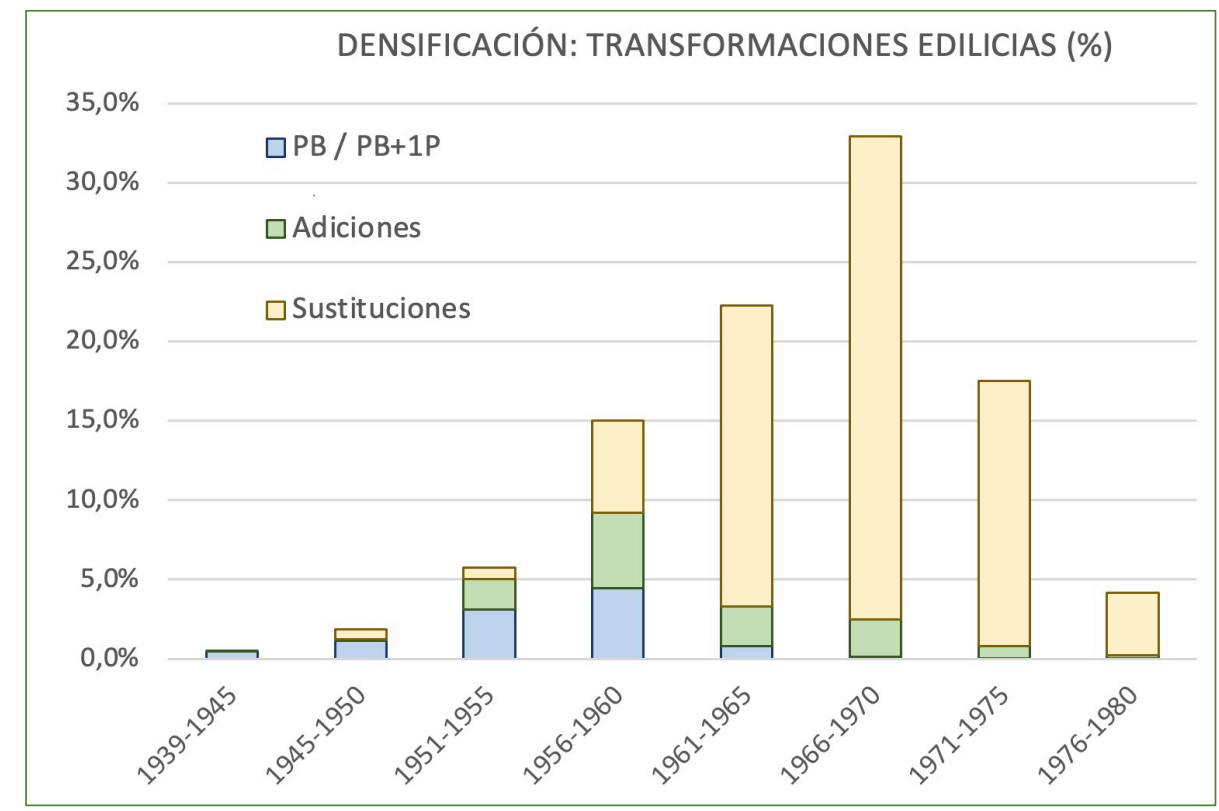

Figura 13. Edificación menuda, adiciones y sustituciones por quinquenios, 1939-1980. Fuente: Elaboración propia a partir de las licencias (AMC) y datos del catastro.

La comparación de ese proceso edilicio que a manera de palimpsesto fue superponiendo capas nuevas de edificación plurifamiliar sobre el tejido de vivienda unifamiliar presentó también dinámicas diferentes en los barrios más centrales y en los más alejados. Las curvas comparadas de los dos barrios más importantes de cada uno de los dos agregados, Vilapicina-Fabra y Puig respecto al barrio de Prosperitat (en las que no hay distorsiones por el impacto de polígonos) lo ponen claramente en evidencia (figura 14). En la década de los cincuenta Vilapicina sobrepasó la Prosperitat en un 55\% de nueva vivienda, la mayor parte adiciones de casas sobre las preexistentes $\mathrm{y}$, sobre todo, sustituciones del caserío unifamiliar con casas altas entre medianeras. En el decenio de los sesenta se observa que mientras la curva de Vilapicina se mantiene en una meseta con elevaciones en torno a las 450-600 viviendas, el intensísimo ciclo de densificación de Prosperitat (figura 12) tomó forma de un elevado doble pico cercano al millar de unidades a finales de los sesenta. Eso arrojó un $82 \%$ más de vivienda durante la década. Si miramos la década siguiente observaremos que de nuevo en los setenta la curva de Vilapicina tomará la delantera sin discusión: un $82 \%$ más de nuevos alojamientos. 
En definitiva, la alternancia entre densificación central y densificación periférica nos vuelve a mostrar las mismas lógicas de crecimiento alternado de fuera a dentro observadas al analizar la oposición norte-sur. Si el proceso de creación de nueva vivienda fue siempre de afuera a dentro, el de densificación fue de dentro a fuera.

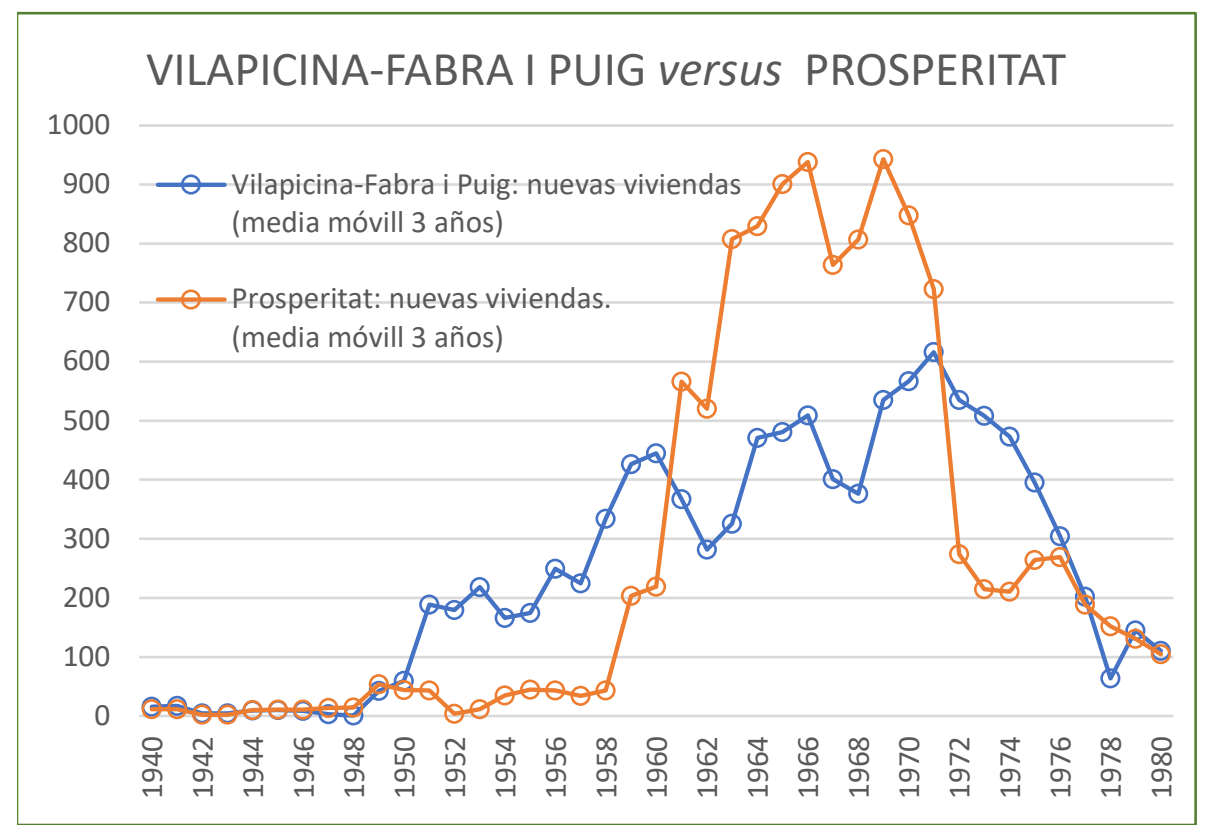

Figura 14. Vilapicina/Fabra i Puig frente a Prosperitat, 1940-1980: Densificación progresivadurante el ciclo largo frente a densificación concentrada en los sesenta. Fuente: Elaboración propia a partir de las licencias (AMCB) y datos del catastro

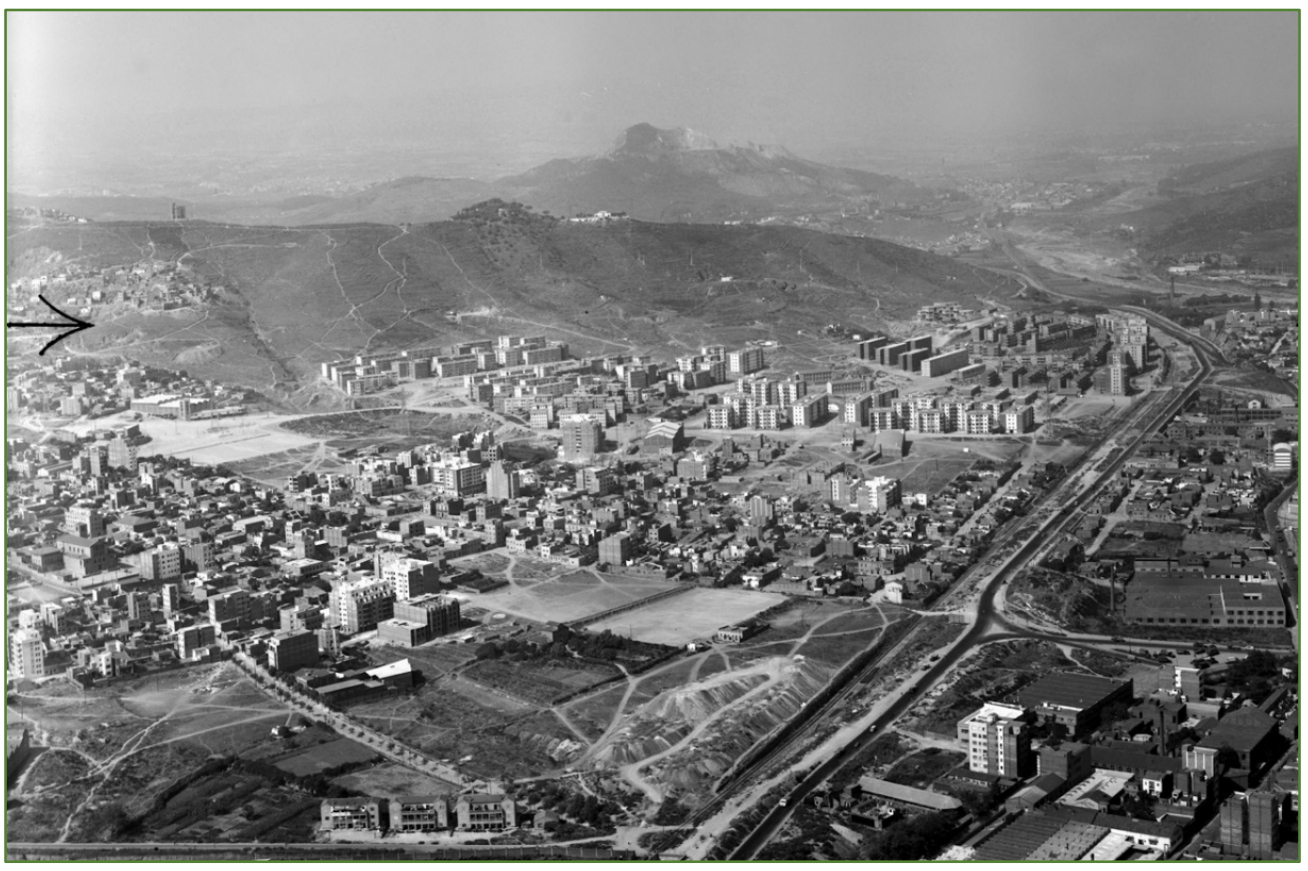

Figura 15. Vista general de Nou Barris, 1966.

Fuente: Fondo TAF (Trabajos Aéreos y Fotogramétricos), Arxiu Nacional de Catalunya 


\section{El “efecto polígono" y los factores críticos en la densificación}

Los datos estadísticos municipales de 1970 revelan lo que podríamos llamar un "efecto polígono" (igura 16). Por ejemplo, la mayor carencia de dotación de agua de los barrios de autoconstrucción, como la Guineueta Vella (Canyelles) con el 87,6\% de viviendas sin dotación agua, Torre Baró (59,6\%) y Vallbona (57,6\%), contrasta con la de los barrios dominados por polígonos. Incluso el temprano y humilde polígono de Can Peguera no tiene ningún domicilio sin agua. El 6,2\% de hogares sin agua del barrio de Can Ensenya se debe a los viejos tejidos preexistentes de las calles Riba-roja, Mont-ral y Vilalba, hoy desaparecidos, como se puede comprobar en los datos por secciones censales

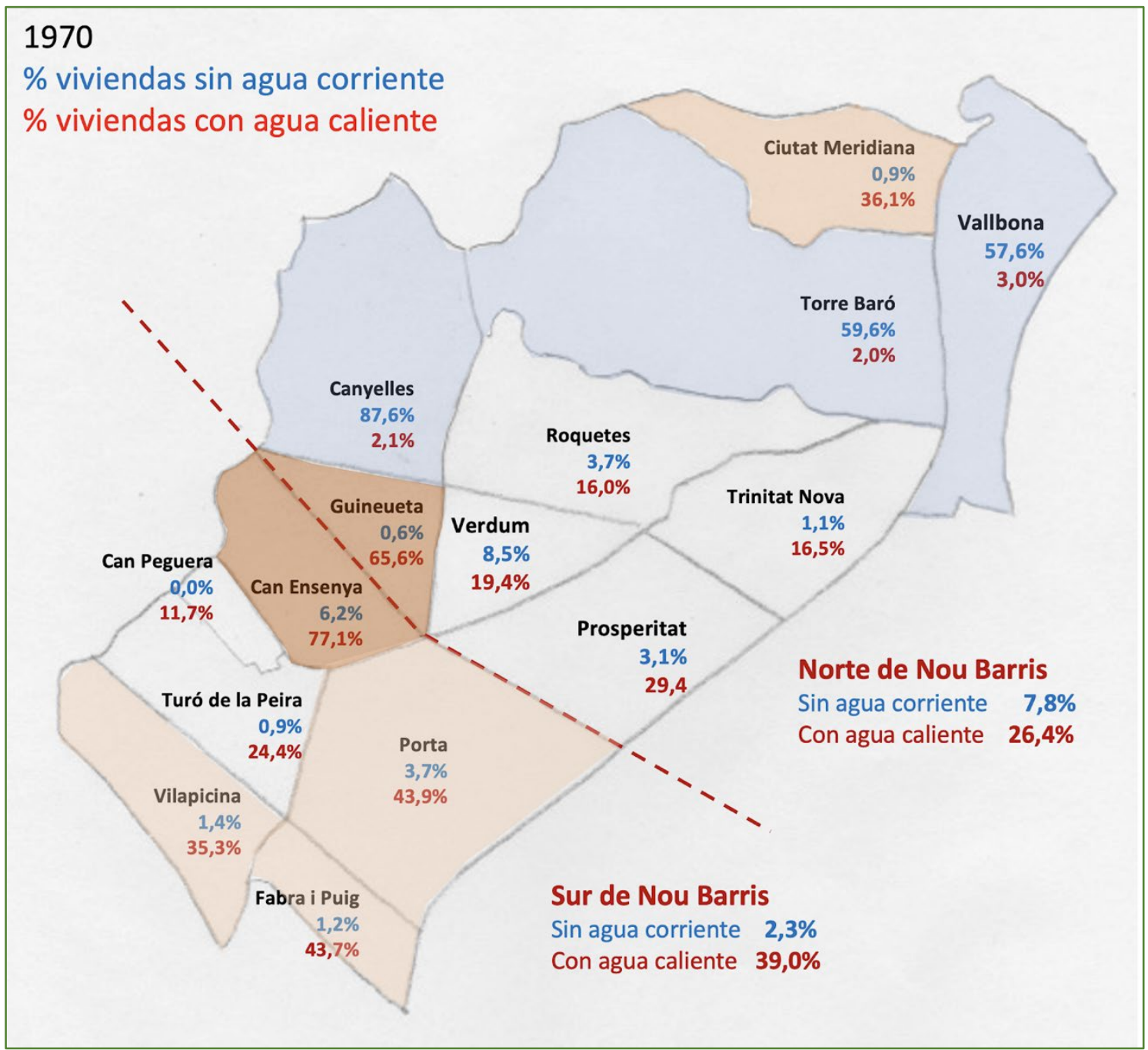

Figura 16. Nou Barris: abastecimiento de agua y de agua caliente, zonas norte/sur y por barrios, 1970. Fuente: Elaboración propia a partir del Cens d'habitatges de Barcelona, Departament d'Estadística i Difusió de Dades (Oficina Municipal de Dades, Ajuntament de Barcelona).

El área de Roquetes, Verdum y Prosperitat ofrece evidencias tempranas sobre la importancia crítica de las infraestructuras de agua y alcantarillado y sobre el 'efecto polígono'. Las ordenanzas eran explícitas: sin dotación de agua corriente y presencia de alcantarillado solo se aceptaban casas unifamiliares (Ordenanzas de Edificación 1947, Art 
410.) Estas infraestructuras fueron sin duda factores críticos en el proceso de sustitución de casas unifamiliares por inmuebles plurifamiliares.

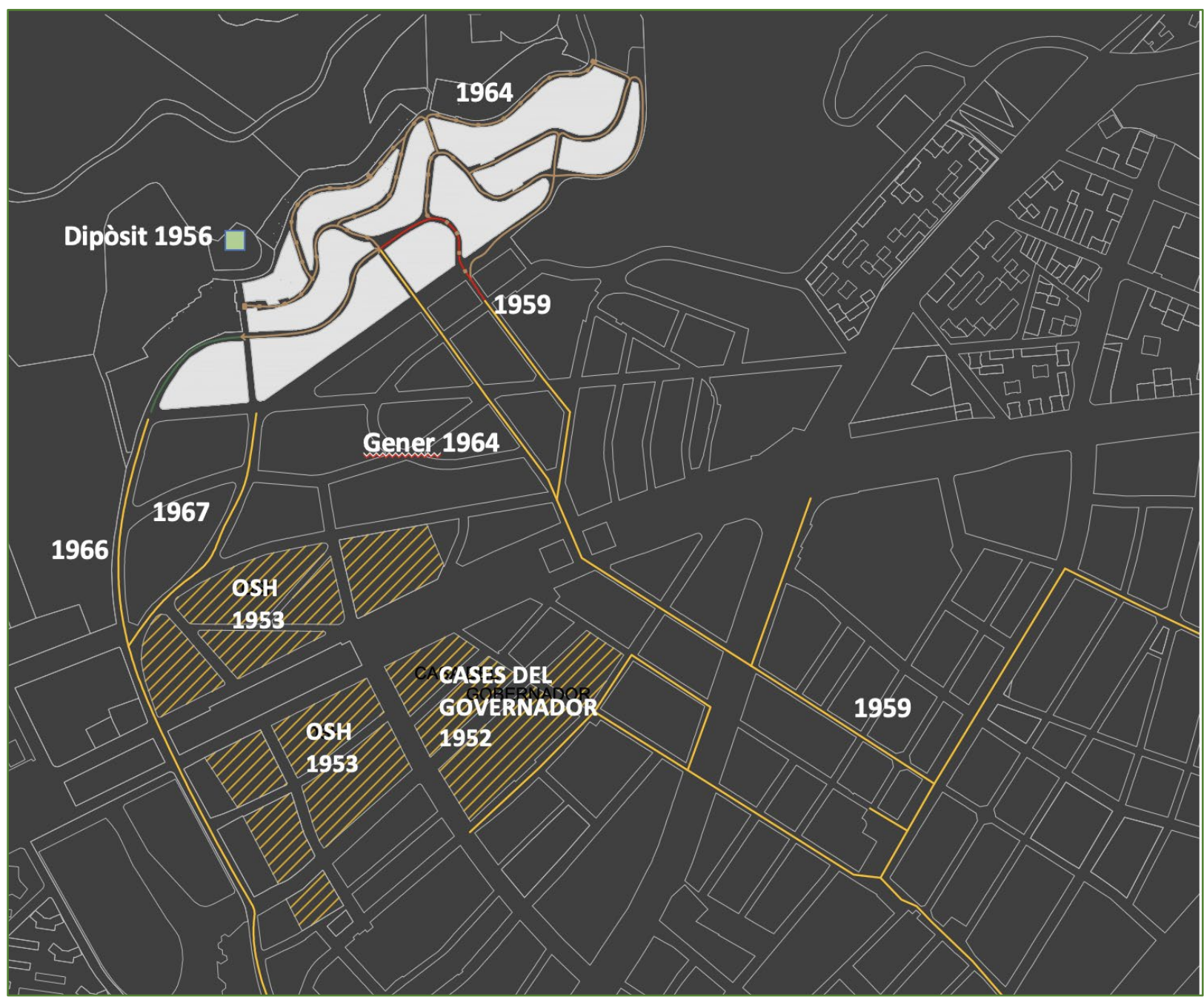

Figura 17. Alcantarillado en Prosperitat, Verdum y Roquetes, 1956-1959.

Fuente: Elaboración propia

En toda esta amplia zona, el único colector anterior a los construidos en 1959 durante el Plan de Urgencia fue el de las calles Batllori-Argullós, instalado con toda probabilidad para servir las casas del Gobernador y el grupo de la Obra Sindical del Hogar (Figura 17). Es todavía más sintomática la instalación de una central de elevación de agua corriente desde una parcela de la calle Argullós hasta el nuevo depósito en la parte alta de Roquetes, por encima de la calle Llobera, justamente en 1956, el mismo año que empiezan a ser ocupadas las viviendas de la OSH, iniciadas en 1953. Parece claro que este primer alcantarillado y el refuerzo en la dotación de agua estuvieron estrechamente vinculados a estos polígonos. Hasta la década de 1960 no se completó el sistema de alcantarillado de la zona. De modo que, en 1970, la situación había cambiado radicalmente y los porcentajes de viviendas sin agua en estos barrios eran ya bajísimos.

También las zonas servidas por la red de gas ciudad son significativas (Figura 18). En la zona sur con un $35,7 \%$ de las viviendas conectadas a la red solo Can Peguera queda al 
margen. En cambio, en toda la zona norte su 12,9\%, es un engañoso porcentaje causado por Ciutat Meridiana con un 76,12\% y el polígono de la Guineueta con un 20\% de las viviendas servidas por gas ciudad. En el resto de barrios los porcentajes son extremadamente bajos. En esta zona norte, son los grandes polígonos los únicos servidos por la red de gas y, aunque son conocidas las protestas vecinales por los problemas de la red de gas de Ciutat Meridiana, sus infraestructuras contrastan fuertemente con la absoluta ausencia de ellas en los inmediatos barrios de Torre Baró y Vallbona.

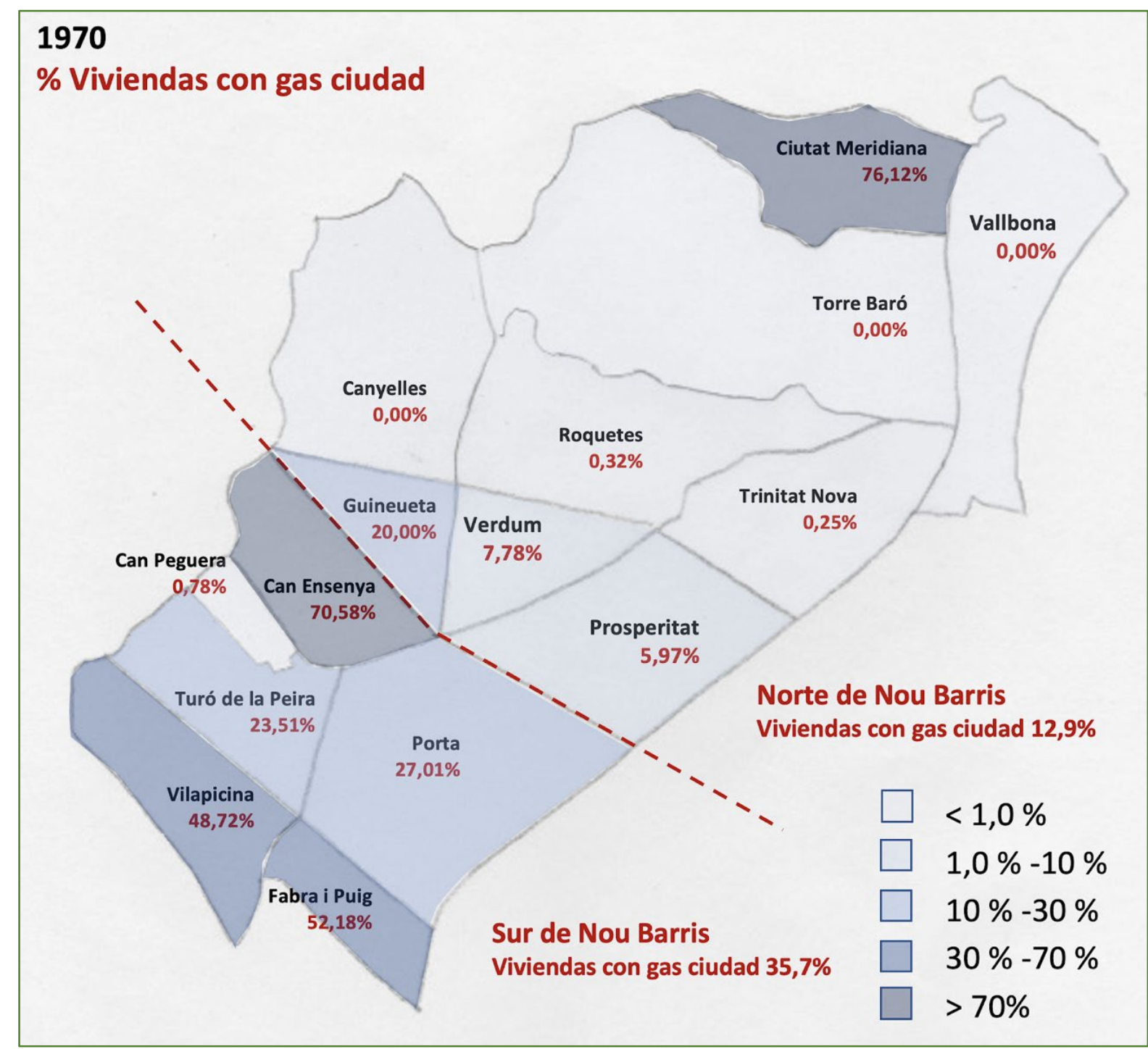

Figura 18. Nou Barris: abastecimiento de gas ciudad, zonas norte/sur y por barrios, 1970.

Fuente: Elaboración propia a partir del Cens d'habitatges de Barcelona, Departament d'Estadística i Difusió de Dades (Oficina Municipal de dades, Ajuntament de Barcelona).

Los porcentajes de viviendas con agua caliente vuelven a mostrar las dos lógicas: el contraste sur/norte y lo que hemos llamado 'efecto polígono'. Los barrios del sur suman un $39 \%$ de viviendas con agua caliente, mientras en el norte solo alcanza un $26,4 \%$. En general, los polígonos más recientes son las áreas mejor servidas: Guineueta con un 36,1\% de viviendas con agua caliente, Ciutat Meridiana con un 36,1\% y Can Ensenya con un 77,1\%. 


\section{La renovada polaridad centro/periferia}

Desde el mismo surgimiento de Nou Barris, el grado de accesibilidad contribuyó de forma decisiva al contraste sur/norte que hemos venido observando. Los barrios del sur siempre habían estado mejor conectados con el resto de la ciudad. La evolución posterior de las infraestructuras de transporte público fue clave en la renovación de esta polaridad (figura 19). En el año 1959, tres cambios facilitaron el acceso a Nou Barris. Se inauguró la línea subterránea del ferrocarril bajo la Meridiana, hasta entonces en superficie, y el apeadero de 1909 se transformó en la estación de Renfe de Sant Andreu-Arenal. En 1959 se inauguró también la nueva línea de metro, con cinco paradas: Sagrera, Viviendas del Congreso, Maragall, Virrei Amat y Vilapicina. Entró también en funcionamiento la primera línea de tranvía entre la plaza de Virrei Amat y la plaza de Llucmajor (hoy plaza de la República), que en aquel momento era un simple descampado. Servía de forma inmediata los dos grandes polígonos impulsados por el Plan de Urgencia de 1958, entonces en proceso, y acercaba el transporte público a los barrios de Prosperitat, Verdum, Roquetes (en menor medida, a Trinitat Nova). La nueva línea contribuyó sin duda a la espectacular densificación de esos barrios en los años sesenta.

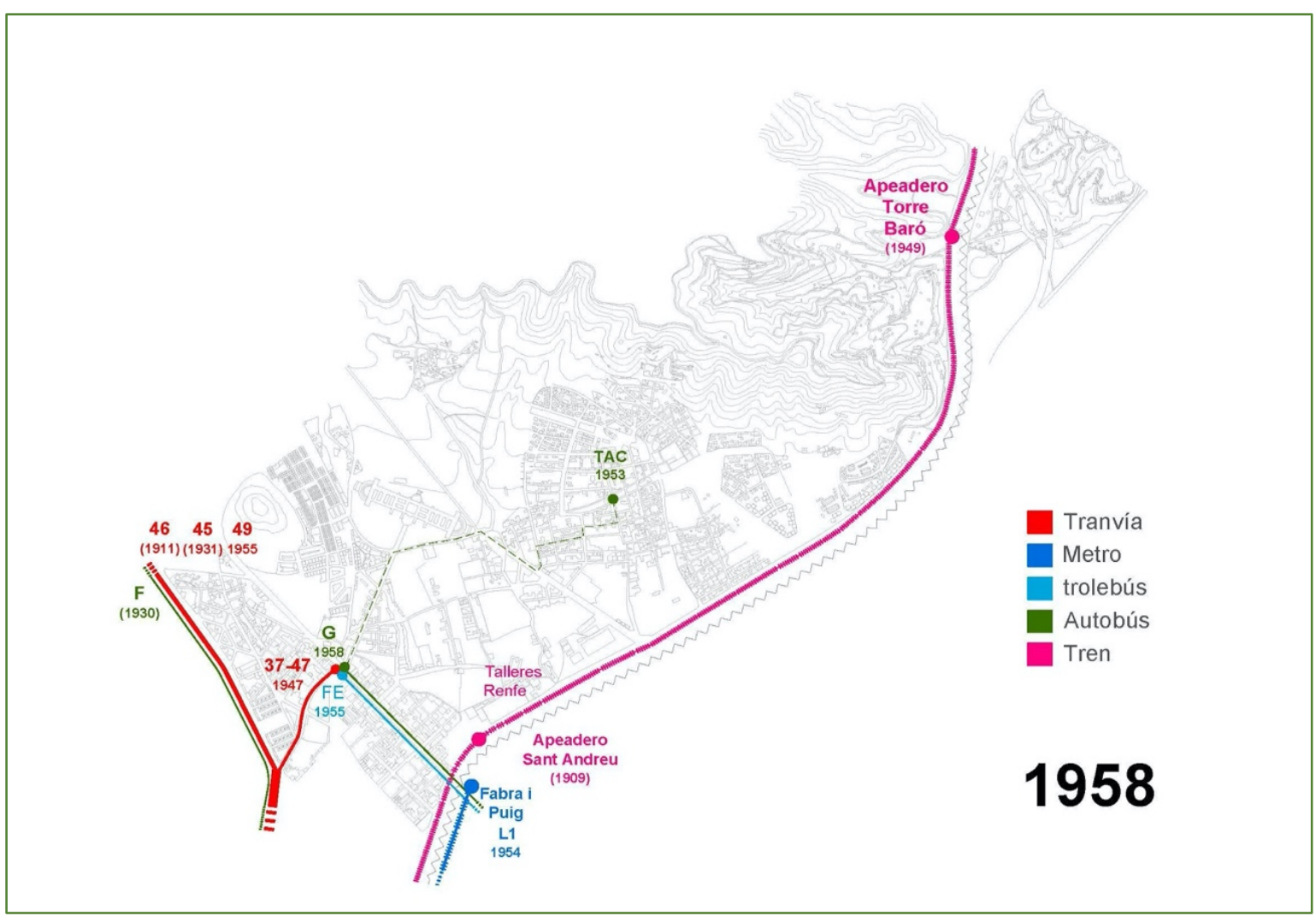




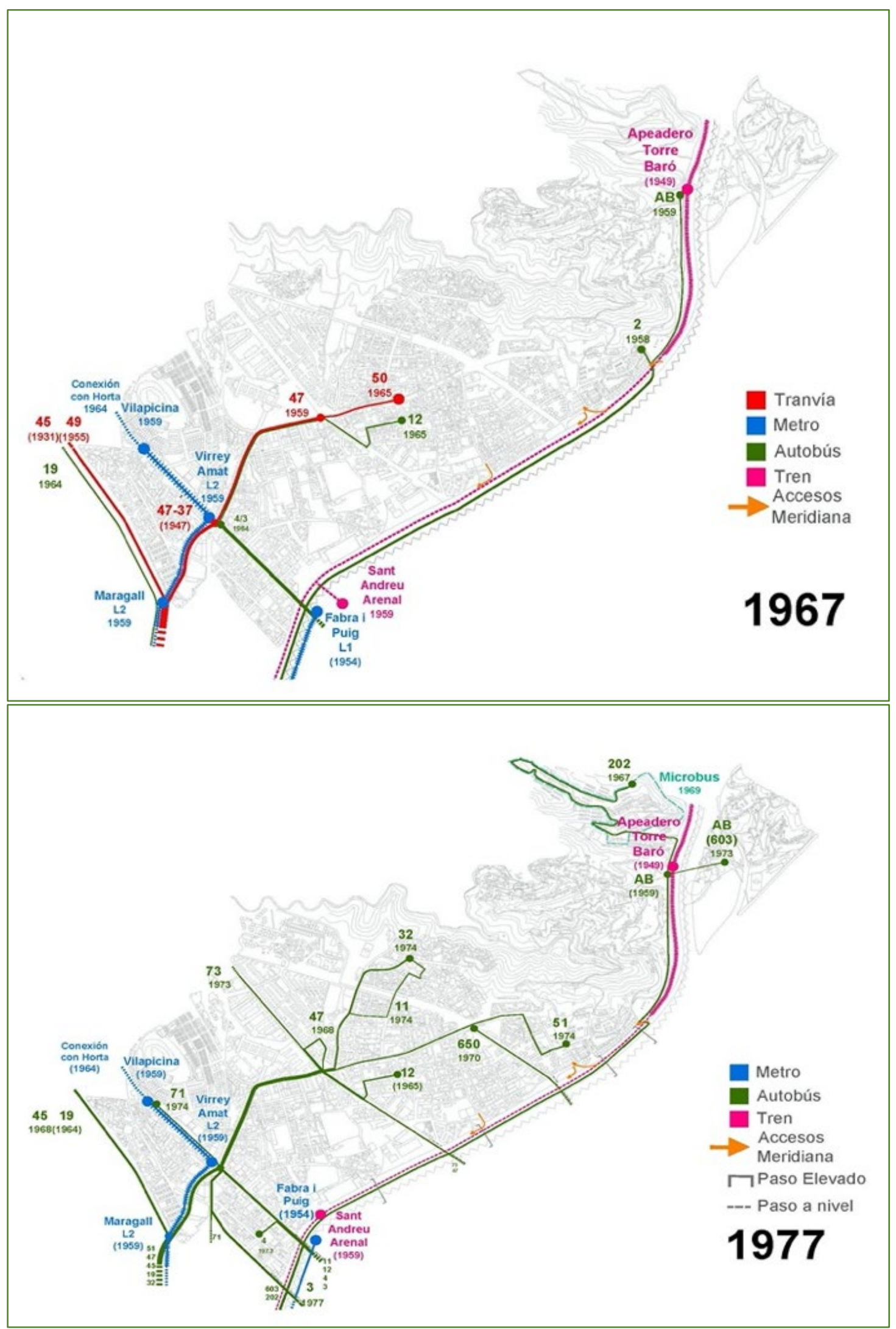

Figura 19. La evolución de norte a sur de los sistemas de transporte en Nou Barris, 1958, 1967, 1977.

Fuente: Elaboración propia a partir de la publicación de Ricard Fernández, Destinació: Nou Barris. Un viatge per la història dels transports a Nou Barris, 2010. 
Con todo, la nueva accesibilidad ganada por esos barrios del norte supuso también un incremento de la centralidad de la zona sur. La prolongación en 1965 de la línea de tranvía por Vía Júlia hasta Vía Favencia mejoraba la accesibilidad a Trinitat Nova, pero acentuaba todavía más la centralidad de Virrei Amat, ya muy reforzada tras la prolongación en 1964 de la línea de metro entre Vilapicina y Horta, que la convertía en centro de conexiones e intercambios entre metro, tranvías y autobuses. Los pagos de radicación en 1977 del comercio al detall confirman significativamente las polaridades comerciales asociadas a esa zona sur, siempre mucho más central, accesible y dotada (Figura 20).

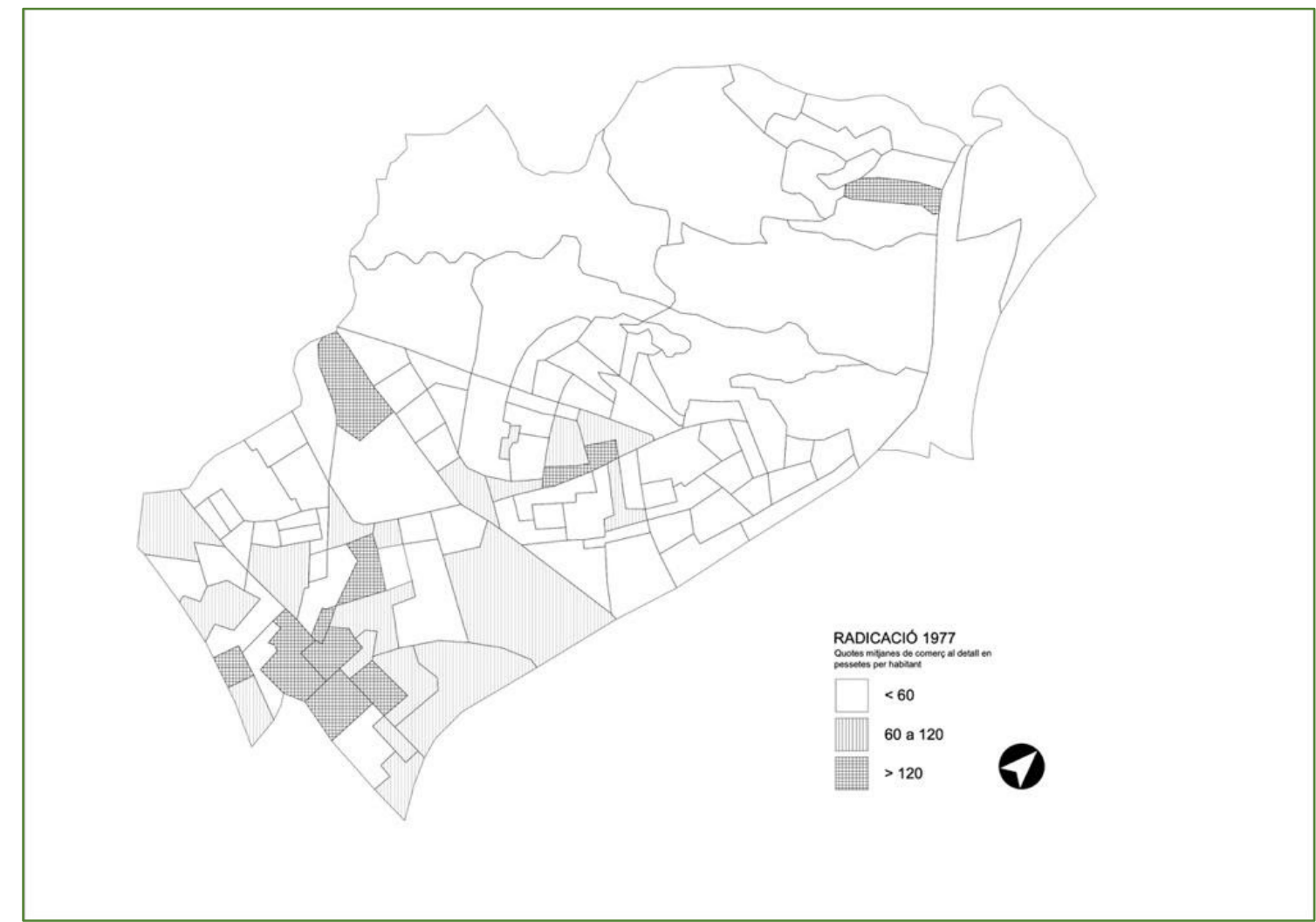

Figura 20. La polaridad comercial del sur, 1977.

Fuente: Elaboración propia a partir de datos digitalizados del Impuesto de radicación, facilitados por el Departament d’Estadística Difusió de Dades (Oficina Municipal de Dades, Ajuntament de Barcelona)

\section{El norte y el sur del distrito más obrero de Barcelona}

En el momento final de la explosión residencial barcelonesa, en 1975, los barrios más obreros de la ciudad (con porcentajes de clases trabajadoras entre el 60 y $70 \%$ de su población) se concentraban claramente en los extremos del término municipal (Montjuïc, Zona Franca, Besòs, Bon Pastor, Horta y Porta). Con un 70\% de clases trabajadoras entre su población, Nou Barris era sin dudar el conjunto de barriadas más obrero de Barcelona (Oyón, Guàrdia, Rosselló, H. Falagán y Roger 2021).

En la ciudad se acusaba un proceso de imparable descenso del peso de los trabajadores y las trabajadoras manuales (menos ya de la mitad en 1975 y sólo un 39\% una 
década después). Nou Barris mantuvo, sin embargo, su carácter mayoritariamente obrero. Según los padrones de 1970 y 1975, sólo en un 6\% de las 113 secciones censales de Nou Barris era minoría la población activa no dedicada al trabajo manual. Aunque había descendido en más de diez puntos sobre el 83\% de población trabajadora de 1950, alejándose algo de la proporción obrera en los municipios periféricos del área metropolitana (entre el 72 y el 78\%, y por encima del 80\% en algunas ciudades como Santa Coloma, Sant Joan Despi, Viladecans, Sant Boi o Ripollet) (Roca 1986, cuadros 35, 114; Izquierdo, Miguélez, y Subirats 1988). Ese tímido movimiento de diversificación social que muestran las cifras resalta mucho más al desplazarnos del norte al sur, de la corona exterior a la interior del distrito. Como muestra el plano adjunto (figura 21), el norte era en 1975 homogénea y masivamente obrero. El plano dibuja una gama de intensidades donde la condición obrera alcanzaba sus máximos en el extremo norte (en los barrios de autoconstrucción de Torre Baró y Vallbona) y los mínimos en el extremo sur (en la zona de Vilapicina/Fabra y Puig). La crisis económica de mediados de los setenta y el consiguiente vaciado poblacional posterior de algunas secciones de Nou Barris irán aparejados al reforzamiento de esa tendencia de desproletarización del sector sur: en 1978 un 63\% de todas sus secciones censales ya no son mayoritariamente obreras, la práctica totalidad en el caso de Vilapicina/Fabra i Puig.

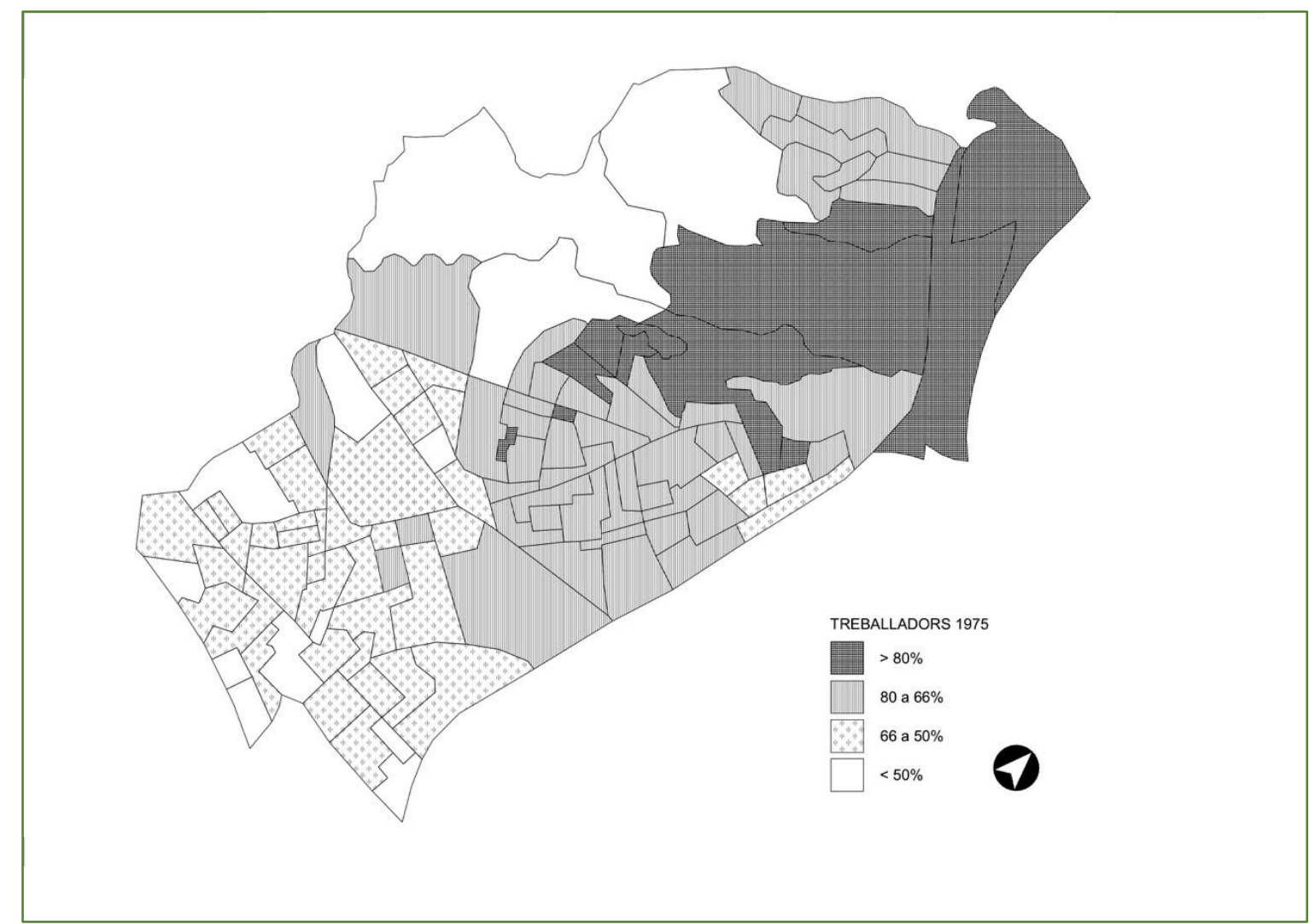

Figura 21. Porcentaje de trabajadores y trabajadoras manuales por sección censal (1975).

Fuente: Elaboración propia a partir del Padrón de Barcelona, Departament d’Estadística i Difusió de Dades (Oficina Municipal de dades, Ajuntament de Barcelona).

Los planos por barrios explican la misma historia de progresiva desproletarización de la parte sur (Figura 22). Cuando en la ciudad era ya minoritaria la condición obrera, dos de cada tres activos de Nou Barris en 1970 era todavía trabajador o trabajadora. Pero la 
situación variaba mucho en la corona exterior o la interior: casi tres de cada cuatro al norte y menos del 58\% al sur. En 1978, con casi diez puntos menos de población obrera en el conjunto de Nou Barris, las diferencias entre norte y sur todavía persistían, hasta el punto que en el conjunto de barriadas del sur era ya minoría la población obrera $(48,2 \%)$.

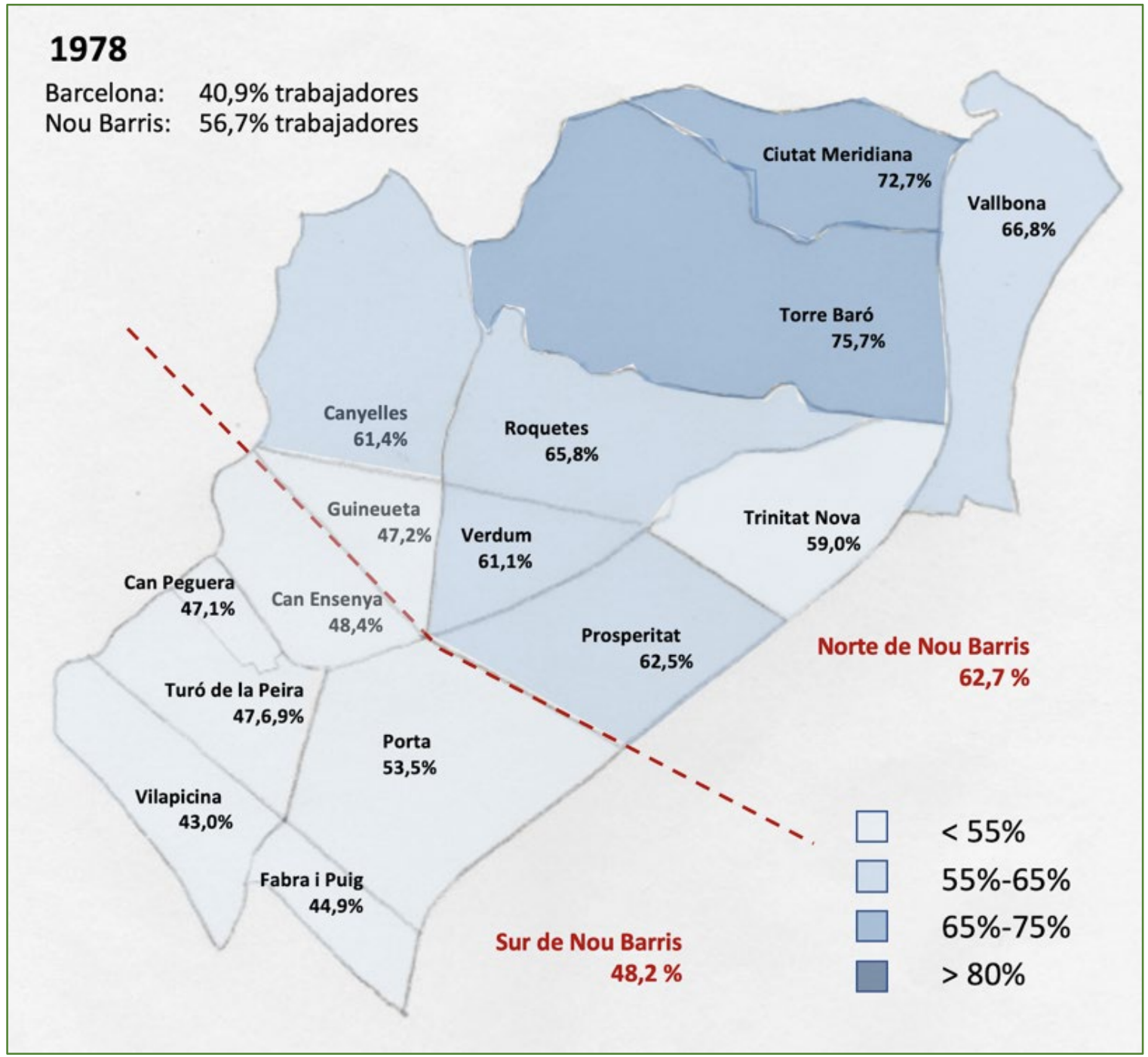

Figura 22. Porcentaje de trabajadores y trabajadoras manuales por barrio, 1978.

Fuente: Elaboración propia a partir del Padrón de Barcelona, Departament d’Estadística i Difusió de Dades (Oficina Municipal de dades, Ajuntament de Barcelona).

\section{Vivienda obrera y propiedad horizontal}

En clara divergencia a lo sucedido en Europa, en las grandes ciudades españolas se consolidaron durante el franquismo altos porcentajes de vivienda en propiedad en las capas obreras (Candela 2019). Las nuevas barriadas obreras periféricas se convirtieron en la "infantería de la propiedad" (Tatjer 2005; Oyón, Guàrdia, Rosselló, H. Falagán y Roger 2021). 


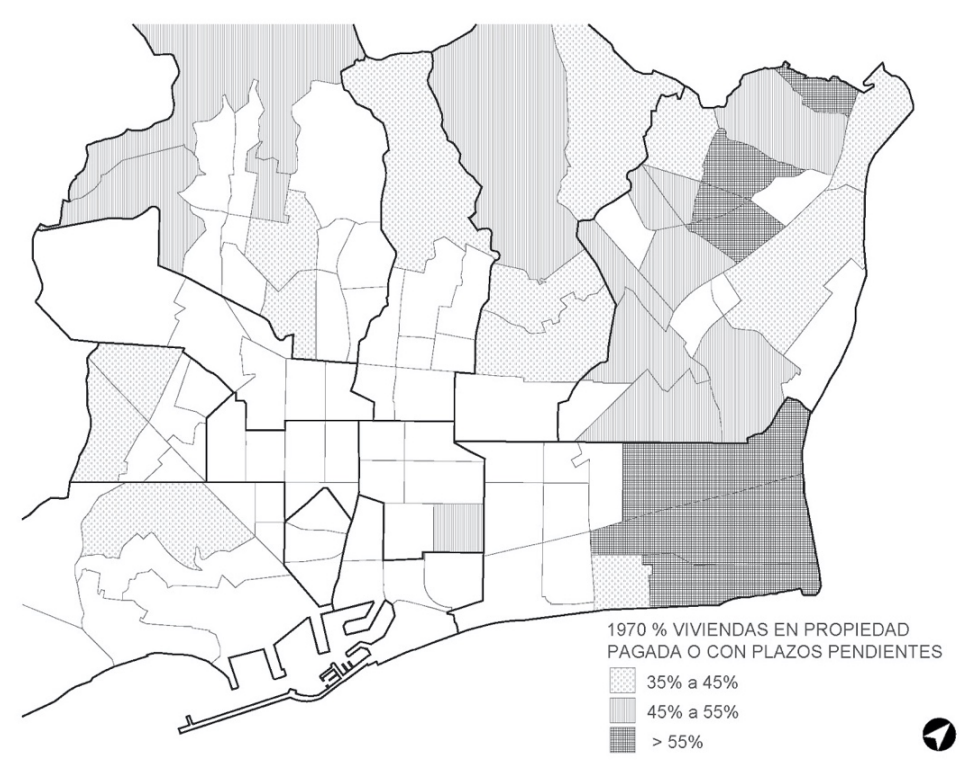

1970

\% DE PROPIEDAD PAGADA O CON PLAZOS PENDIENTES

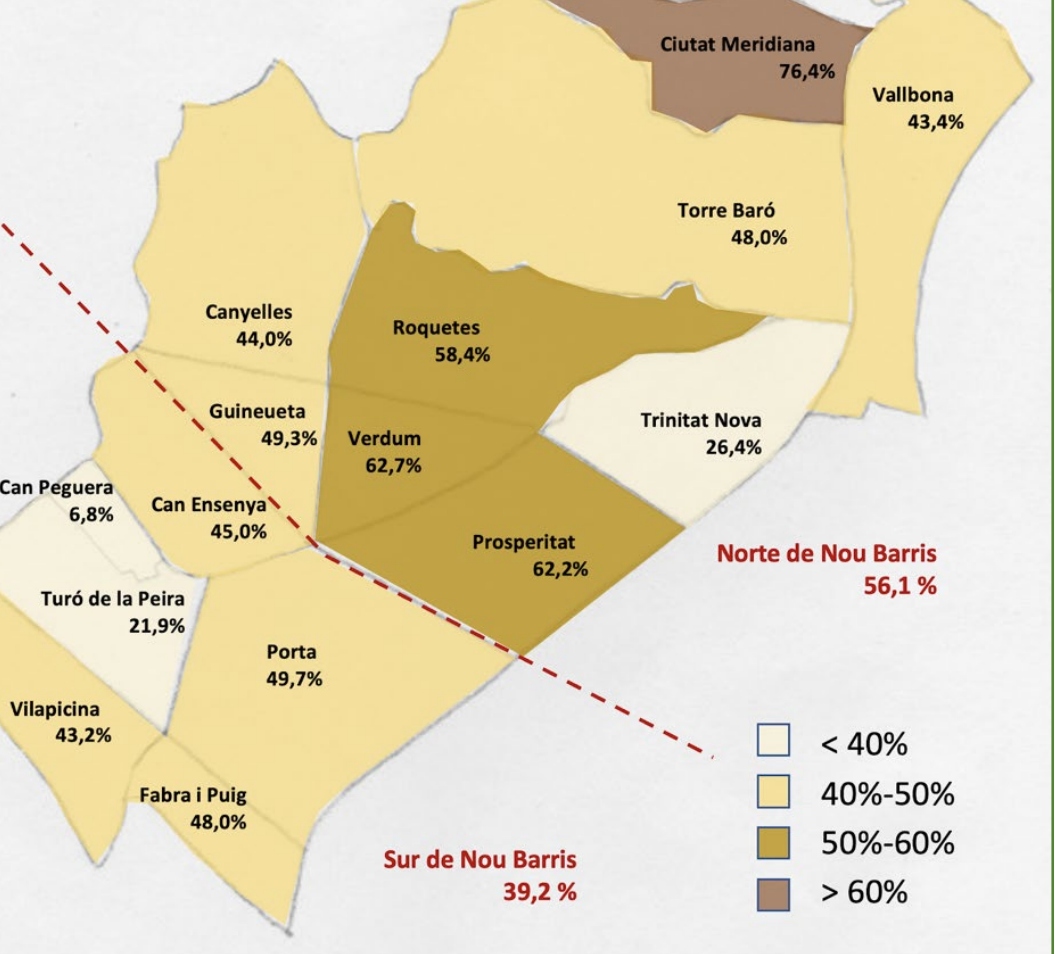

Figura 23. Porcentajes de propiedad por distritos y barrios administrativos en Barcelona y por barrios en Nou Barris, 1970.

Fuente: Elaboración propia a partir del Cens d'habitatges de Barcelona, Departament d'Estadística i Difusió de Dades (Oficina Municipal de dades, Ajuntament de Barcelona). 
En 1930 el índice de propietarios entre los hogares obreros era muy ligeramente inferior a la media urbana del 5,2\% y sólo existían algunas bolsas de pequeños propietarios obreros de casitas de planta baja en las parcelaciones de laderas de Collserola, precisamente en la zona de Nou Barris (Oyón y Garcia 1998, 47-84). Herencia de la situación de entreguerras, Nou Barris según el vaciado del Padrón de 1950 mantenía índices de propiedad del 23\%. Pero en 1965, los distritos obreros 9 y 10 estaban ya a la cabeza del piso en propiedad con un $28,6 \%$ y un $26,6 \%$ respectivamente, esencialmente nueva propiedad. En los barrios administrativos del futuro distrito de Nou Barris, la propiedad sobrepasaba entonces el 29\%: 32,8\% en Santa Eulàlia y 25,3\% en Les Roquetes (figura 23). Cuando en 1970 la vivienda en alquiler en la ciudad todavía superaba en casi 30 puntos porcentuales a la vivienda en propiedad, esos distritos obreros habían tomado ya la delantera en la carrera hacia la posesión de un piso. Un análisis del millar de secciones del censo de edificios de 1970 (propiedad pagada o con pagos pendientes) muestra a las claras la correlación negativa entre propiedad y clases acomodadas $(-0,26)$. La de las clases trabajadoras era en cambio netamente positiva $(+0.32)$ llegando al $+0,39$ en los cinco distritos periféricos de la ciudad. El impacto de la Ley de la Propiedad Horizontal de 1960 en el mundo obrero estaba siendo realmente extraordinario, particularmente en las nuevas barriadas periféricas. En 1970, el distrito noveno tenía ya 45.113 hogares en propiedad o con plazos pendientes (un 44,7\%) frente a 43.934 hogares en alquiler (un 43,5\%). En Nou Barris el avance será todavía mayor, con una tasa de vivienda en propiedad del 48,4\%, cuando en el conjunto de Barcelona era del 31\%. A la salida de la crisis, la Enquesta Metropolitana de 1986 lo confirmaba: un 69\% de toda su población había accedido ya a la vivienda propia (Izquierdo, Miguélez y Subirats 1988, 56-57).

El reparto de la vivienda en propiedad por secciones censales y barrios confirma también las diferencias entre la corona exterior e interior de Nou Barris que han ido apareciendo en este artículo. El sector norte tenía en 1970 una tasa de vivienda en propiedad del $56,1 \%$, claramente por encima de la media del actual distrito $(48,4 \%)$. El sector sur en cambio la tenía visiblemente por debajo, un 39,2\%, idéntica a la del resto del distrito IX.

Otro de los rasgos diferenciadores del norte de Nou Barris fue la presencia de un alto porcentaje de vivienda en propiedad imperfecta. No se trataba solo de la población de los barrios de vivienda autoconstruida que, como Torre Baró, Vallbona y Roquetes Altes habían luchado desde los años cuarenta por poder acreditar con papeles la legalidad de los contratos de compra de sus parcelas y por acceder así al derecho a disponer de unas infraestructuras y equipamientos que nunca llegaban por esa condición de ilegalidad. Era también el caso de la propiedad diferida de los polígonos de la Obra Sindical del Hogar construidos en los años cincuenta, como el de la Trinitat Nova, con la inseguridad jurídica y la falta de una clara delimitación de obligaciones en caso de problemas de construcción de origen y falta de servicios complementarios. Es lo que hizo estallar las huelgas de pago de cuotas de amortización de la vivienda en varios polígonos de la OSH en el área metropolitana entre 1969 y 1973. 


\section{La defensa de la propiedad y las luchas vecinales}

Aunque generalmente soslayada por la historiografía de los movimientos urbanos y rompiendo con la vieja tradición de las huelgas de alquileres, la propiedad (a menudo precaria o imperfecta) emerge desde el segundo franquismo como una variable relevante a la hora de analizar las diversas fases y modalidades de las acciones vecinales (Trilla 2017). Si observamos el caso de Nou Barris, los primeros en organizarse serán los barrios de autoconstrucción de las dos décadas posteriores a la guerra (Cuesta 2014, 142 y ss). Donde los vecinos, unidos por una común condición de una propiedad todavía en precario estado desde el punto de vista legal, con un equipamiento doméstico incompleto, se organizan para construir en común infraestructuras básicas como el alcantarillado. Este es el caso de los vecinos del área autoconstruida de Roquetas Altas (Nou Barris), donde los propietarios aprovecharon los días festivos del verano de 1964 para autoconstruir las infraestructuras básicas de alcantarillado y de agua corriente. Fue el origen de la articulación vecinal que continuará su lucha en los años sucesivos. Es también el caso de la asociación de vecinos creada por esas mismas fechas en el barrio autoconstruido de Ca n'Oriach de Sabadell (Domènech 2002, 137-139). En los polígonos de la Obra Sindical del Hogar del área metropolitana, construidos en los cincuenta, la inseguridad jurídica del confuso régimen de propiedad aplazada fue el determinante de las movilizaciones entre 1969 y 1973. Las huelgas de pago de cuotas de amortización de la vivienda en Trinitat Nova y Verdum son el mejor ejemplo de ese tipo de acción colectiva, aislada al principio, pero coordinada luego con otros polígonos del área metropolitana y de la propia Barcelona (Dols, 1974, 74-81. AAVV 'Separata...'1975).

Esos barrios pasaron del asistencialismo de los centros parroquiales y sociales al fortalecimiento de estructuras vecinales autónomas, y finalmente al planteamiento de conflictos y acciones colectivas que desbordaban la estrecha legalidad franquista (Bordetas 2009, 73-92). Podrían inscribirse en esta lógica las manifestaciones por la inseguridad vial y la falta de semáforos, o las ocupaciones de la autopista Barcelona-Granollers a finales de 1969, también en 1971, por los vecinos de Torre Baró y Vallbona por los problemas de falta de conexión entre dos barrios históricamente unidos (Bordetas 2009, 101-102). Ese tipo de acción colectiva culminaría en numerosos barrios periféricos en la formación de Asociaciones de Vecinos cada vez más fuertes y decididas.

A finales de los años sesenta, el Ayuntamiento promovió un plan parcial conocido como el Plan de Torre Baró y Vallbona, que afectaba a los barrios del norte del actual distrito, con la reforma de grandes vías y con la reserva de espacios para grandes operaciones inmobiliarias y comportaba la posible destrucción de más de 4.000 viviendas. Ante la amenaza sobre la insegura propiedad de las viviendas la movilización fue inmediata y radical. La Asociación de Vecinos del sector Trinidad-Torre Baró-Vallbona que articulaba las protestas pronto adoptó el nombre de '9 Barrios', en referencia a los nueve barrios afectados por el plan parcial. Se manifestaron cortando la Meridiana, incluso invadiendo el pleno municipal y provocando la posterior caída de diversos alcaldes. 
Del ejemplo de Nou Barris, se puede inferir que la posesión imperfecta de la vivienda en propiedad, derivada de la autoconstrucción o de las promociones de la Obra Sindical del Hogar, estuvo en el origen de muchas de las luchas vecinales durante el segundo franquismo. Y en Nou Barris su radicalidad se movió de "norte a sur", de los 'nueve barrios' más obreros, de propiedad más imperfecta y más luchadores a los meridionales de mejor nivel económico y de propiedad más ortodoxa. El mismo nombre del distrito, creado en 1983, se identifica con el nombre de la asociación de vecinos de los nueve barrios del norte, la más combativa.

\section{Conclusión}

Éste es un artículo preliminar de una investigación que, con el objetivo de establecer puentes entre la construcción física y la construcción social de las periferias residenciales obreras, se ha propuesto trabajar sobre una gran variedad de fuentes documentales y aportar nuevos elementos de reflexión al estado de la cuestión. Las restricciones motivadas por la pandemia no han permitido abordar, con la profundidad y el tiempo requerido, las dos fuentes angulares para vertebrar las relaciones entre formación física de estos barrios, y la evolución de sus contenidos sociales. El vaciado sistemático de los padrones de 1940, 1950, 1960 y 1960, que estamos completando, y las entrevistas previstas inicialmente que han quedado en suspenso hasta que no presenten riesgos de contagio, son dos fuentes muy laboriosas que requieren de tiempo.

En esta primera aproximación, el análisis del material empírico disponible, muy condicionado por la documentación que se había podido obtener en la fase previa al estallido epidémico, no apuntaba tanto a completar un relato ni a verificar hipótesis de partida como a "ampliar el horizonte de nuestras ignorancias y a enriquecer la paleta de nuestros interrogantes" (Veyne 1971, 141). En primer lugar, se trataba de confirmar la elección de Nou Barris como ejemplo paradigmático de distrito periférico obrero de crecimiento residencial explosivo durante el franquismo. En segundo lugar, desde el punto de vista de la construcción física de estas periferias, siempre se ha parado la atención en la gran presencia de operaciones de vivienda masiva, los polígonos, y, en menor medida, en el fenómeno de la "urbanización marginal". Hemos constatado sin embargo que, al considerar su aportación en número de viviendas, ambas formas de crecimiento fueron claramente superadas por los procesos de densificación de las tramas preexistentes que, en buena medida, actuaron de tejido conjuntivo. Si los polígonos pueden hacer pensar en una cierta tabula rasa, el peso específico de la densificación y las singularidades de la autoconstrucción obligan a destacar la importancia de las herencias, de los condicionantes topográficos, también de las circunstancias, procesos y tiempos de su construcción.

En tercer lugar, las carencias en infraestructuras, urbanización y equipamientos de todo tipo fueron una de las constantes de todo el período y siempre se han considerado entre las principales causas de las grandes movilizaciones vecinales que tanto contribuyeron a la construcción social del Nou Barris. Pero esta no fue su única incidencia. Es importante atender a los tiempos y lugares de implementación de las distintas infraestructuras porque dan pistas sobre las interacciones, los procesos de diferenciación, así como de la articulación interna y externa de estas periferias. Por último, pero no menos importante, es esencial 
destacar el creciente acceso a la propiedad de la vivienda como un factor desatendido que tuvo, sin duda, una considerable incidencia en la construcción social de estos barrios. Es más que significativo que los barrios del norte, más radicales en las luchas vecinales, fueran también los de mayores tasas de propiedad.

\section{Fuentes}

Arxiu Contemporani Municipal de Barcelona (AMCB): Licencias Obra Privada y Licencias de Obra Pública

Estadística Municipal (https://bcnroc.ajuntament.barcelona.cat)

Estadística Municipal: Vivienda 1970, Padrones 1970, 1975 y 1978, Radicación 1977 (datos digitalizados facilitados por Departament d'Estadística i Difusió de Dades-Oficina Municipal de dades, Ajuntament de Barcelona).

Catastro Barcelona (https://www1.sedecatastro.gob.es)

Fotografías aéreas y cartografía.

Actas Sociedad General de Aguas (Archivo AGBAR)

\section{Bibliografía}

AA.VV. Separata de Nou Barris, abril 1975: "Informe barrios Obra Sindical del Hogar, 1973 y "Dos años de lucha contra la OSH: abril 1973-abril 1975".

Bordetas, Iván. 2009. "De la supervivència a la resistència: la gestació del moviment veïnal a la Catalunya franquista" a Martí Marín (dir.), a Memòries del viatge, 1940-1975. Sant Adrià de Besòs: Museu d'Història de la Immigració / Ajuntament.

Brandis, Dolores. 1983. El paisaje residencial de Madrid. Madrid: M.O.P.U.

Busquets, 1999. La urbanización marginal. Barcelona: Universitat Politècnica de Catalunya. Candela, José. 2019. Del pisito a la burbuja inmobiliaria. La herencia cultural falangista de la vivienda en propiedad, 1939-1959. Valencia: Universitat de Valencia.

Canosa, Elia. 1995. La promoción inmobiliaria en la periferia Noreste de Madrid. Madrid: Centro de Gestión Catastral y Cooperación Tributaria-UAM.

Carrasco, Jesús. 1994., Verdum des de l'any 1952, Barcelona: Associació de Veïns de Verdum CEDEC. 1963. "Un barrio de inmigrantes: las Roquetas", Promos núm. 20, 5-9. Barcelona:

Cordiviola, Alberto, Monclús, Javier, García, Carme y Oyón, José Luis. 1993. "La formación de Nou Barris. Dinámica y explosión de la construcción residencial en la periferia barcelonesa, 1897-1935", en III Congrés d'Història de Barcelona, vol.2, p. 559-572. Barcelona: Ajuntament de Barcelona.

Cuesta, José Miguel. 2014. El moviment veïnal al Barcelonès Nord (1954-1987). Universitat Autònoma de Barcelona: Tesis doctoral.

Checa, Martín 1998. "La diócesis de Barcelona en la posguerra entre la reconstrucción de edificios religiosos y la producción inmobiliaria (1942-1962)". En BarcelonaMontréal. Desarrollo urbano comparado, coordinado por Horacio Capel y Paul-André Linteau,, 435-458. Barcelona: Universitat de Barcelona. 
Díez Medina, Carmen y Monclús, Javier. 2020. Ciudad de bloques. Reflexiones retrospectivas sobre los polígonos de vivienda 'modernos'. Madrid: Abada Editores.

Dols, José Antonio. 1974. "La OSH y el usuario. Los barrios de la OSH: crónica de un conflicto", Cuadernos de Arquitectura y Urbanismo, 105, pp. 74-81.

Domènech, Xavier. 2002. Quan el carrer va deixar de ser seu. Moviment obrer, societat civil $i$ canvi polític. Sabadell: Biblioteca Serra d'Or.

Donato, Emili. 1965. "Barrios altos de San Andrés". Cuadernos de Arquitectura y Urbanismo, n $60,19-47$

Duocastella, Rogelio. 1957. Los suburbios 1957: compendio de las ponencias y coloquios desarrollados durante la "Semana", seguido de gráficas y estadísticas. Barcelona: Gráf. Levante

Fabre, Jaume; Huertas Claveria, Josep Maria. 1997. "Nou Barris” en Els barris de Barcelona, Vol. 3. Barcelona: Enciclopèdia Catalana, Ajuntament de Barcelona.

Fernández, Ricard. 2010. Destinació Nou Barris. Un viatge per la història dels transports a Nou Barris. Barcelona: Districte de Nou Barris.

Ferrer, Amador. 1996. Els polígons de Barcelona. Barcelona: Edicions UPC.

Font, Antonio, Cordiviola, Alberto, Monclús, Javier y García, Carme y Oyón, José Luis. 1993. Trabajos de pre-catalogación para la revisión del catálogo de edificios históricos, Distrito de Nou Barris (no publicado) Barcelona: Ajuntament de Barcelona

Garcia, José Luis. 2000. De la urgencia social al negocio inmobiliario. Promoción de viviendas y desarrollo urbano en Valladolid (1960-1992). Ayuntamiento de ValladolidUniversidad de Valladolid.

Gigosos, Pablo y Sarabia, Manuel. 1997. Arquitectura y urbanismo de Valladolid en el siglo XX. Valladolid: Ateneo de Valladolid.

Grau, Marta; Sànchez, Jordi. 2017. Nou Barris desaparegut, Barcelona: Efadós-Ajuntament de Barcelona- Arxiu Històric de Roquetes Nou Barris.

Izquierdo, María Jesús, Miguélez, Fausto y Subirats, Marina (dir.). 1988. Enquesta metropolitana 1986. Condicions de vida i hàbits de la población de l'àrea metropolitana de Barcelona. Vol 9, Nou Barris. Mancomunitat de Municipis de l'Area Metropolitana de Barcelona. Institut d'Estudis Metropolitans de Barcelona.

Juncà, Josep Ma y Puga, José. 1958. "Informe sobre nuevas parroquias en Verdún-Trinidad". Arxiu Diocesà de Barcelona: parroquia no 174 St. Sebastià (hasta 1969, Arxiu Interior). Citado en Checa, 1998.

Llorden, Moisés. 1978. La producción del suelo urbano en Gijón (1860-1975). Oviedo: Colegio Oficial de Arquitectos de León y Asturias.

LUB (Laboratorio de Urbanismo de Barcelona), 1974, Las formas de crecimiento urbano. Barcelona: ETSAB-UPC

Martínez, Ricard. 1999. El moviment veïnal a l'àrea metropolitana de Barcelona durant el tardofranquisme i la transició: el cas de Sabadell (1966-1976). Universitat Pompeu i Fabra: Tesina de Doctorado inédita.

Medina Sáiz, Alfredo. 2004. Promoción inmobiliaria y crecimiento espacial. Santander, 19551974. Santander: Universidad de Cantabria. 
Monclús, Javier y Díez Medina, Carmen. 2016. "Modernist housing estates in European cities of the Western and Eastern Blocs". Planning Perspectives, 31, n. 4, 533-562.

Oyón, José Luis, Guàrdia, Manel, Rosselló, Maribel, H. Falagán, David y Roger, Joan. 2021. La suburbanización de la clase obrera: vivienda, inmigración y movimientos sociales en el área metropolitana de Barcelona, 1918-1975 (en prensa).

Oyón, José Luis. 2008. La quiebra de la ciudad popular. Espacio urbano, inmigración y anarquismo en la Barcelona de entreguerras, 1914-1936. Barcelona: Ediciones del Serbal.

Oyón, José Luis y García, Carme, 1998, "Las segundas periferias, 1918-1936: una geografía preliminar" en Vida obrera en la Barcelona de entreguerras, 1918-1936, 47-83. Barcelona: CCCB.

Roca, Josep. 1986, Los precios del suelo en el ámbito metropolitano, Corporación Metropolitana de Barcelona, Barcelona.

Rodríguez, Isabel. 2001. Vivienda y promoción inmobiliaria en Madrid. Lleida: Universitat de Lleida.

Sambricio, Carlos (ed.) 2003. Un siglo de vivienda social en España (1903-2003). Madrid: Nerea.

Sennett, Richard. 2019. Construir y habitar. Ética para la ciudad. Barcelona: Anagrama.

Solà-Morales, Manuel de. 1997. Las formas del crecimiento urbano. Barcelona: Universitat Politècnica de Catalunya.

Sorribes, Josep. 2015. Valencia 1940-2014: Construcción y destrucción de la ciudad. Valencia: Publicacions de la Universitat de Vàlencia,

Tafunell, Xavier. 1989. "La construcció: una gran indústria i un gran negoci". En Història Econòmica de la Catalunya Contemporània, vol. 6, Segle XX. Indústria, finances $i$ turisme, 211-241. Barcelona: Enciclopèdia Catalana.

Tatjer, Mercè. 2005. "La vivienda obrera en España de los siglos XIX y XX: de la promoción privada a la promoción pública (1853-1975)". Scripta Nova. Revista electrónica de geografía y ciencias sociales. Barcelona: Universidad de Barcelona, vol. IX, núm. 194 (23), 1 de agosto. <http://www.ub.es/geocrit/sn/sn-194-23.htm> [ISSN: 11389788].

Tatjer, Mercè. 1995. La Trinitat Nova, Barcelona: Generalitat de Catalunya- Departament de Benestar Social.

Thió. Santiago, S.J. 2001. Les clavegueres de la part alta del barri de Les Roquetes de Barcelona (1964.1966). Girona: junio (texto inédito, Arxiu Roquetes-Nou Barris).

Trilla, Carme. 2017. "La transformació del règim de tinença de l'habitatge. El cas de Barcelona", Jornada Habitar Barcelona al segle XX: Accés a l'habitatge, veïns i ciutat, 1945-1993, MUHBA-Oliva Artés, 22 març 2017.

Urban, Florian. 2012. Tower and Slab, Histories of Global Mass Housing. London: Routledge, Veyne, Paul. 1971. Comment on écrit l'histoire. Paris: Éditions du Seuil.

Vilagrasa, Joan. 1990. Creixement urbà i agents de la producció de l'espai: el cas de la ciutat de Lleida (1940-1980). Barcelona: Institut Cartográfic de Catalunya, 
Vilagrasa, Joan. (Ed.). 1997. Vivienda y promoción inmobiliaria en España. Lleida: Universitat de Lleida.

Whitehand, Jeremy W. R. 1987. The changing face of cities. A study of Development Cycles and Urban Form. Oxford-New York: Blackwell.

(C) Copyright José Luis Oyón, Manel Guàrdia, Maribel Rosselló, David H. Falagán y Joan Roger Goncé, 2021

(C) Copyright: Scripta Nova, 2021.

Ficha bibliográfica:

OYÓN, José Luis, GUÀRDIA, Manel; ROSSELLÓ, Maribel, FALAGÁN, David H., ROGER GONCÉ, JoanN. La revolución residencial de la periferia obrera en Barcelona, 19391980: Nou Barris como estudio de caso. Scripta Nova. Revista Electrónica de Geografía y Ciencias Sociales. Barcelona: Universitat de Barcelona, vol. 25, Núm. 2 (2021), p. 271 306 [ISSN: 1138-9788]

DOI: $10.1344 / \mathrm{sn} 2021.25 .32407$ 